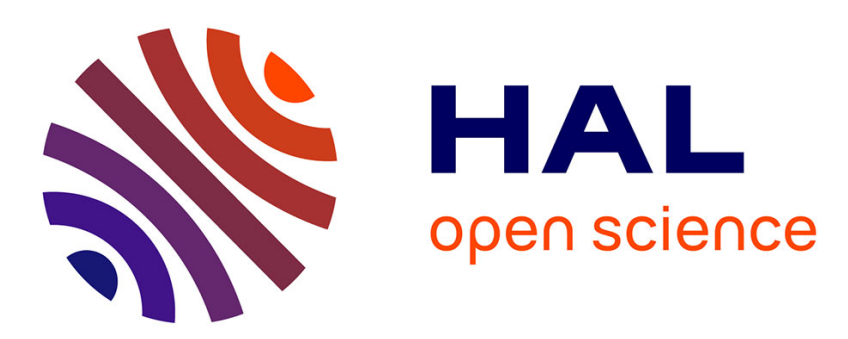

\title{
Joint inversion of hydraulic head and self-potential data associated with harmonic pumping tests
}

\author{
A Soueid Ahmed, Abderrahim Jardani, A Revil, Jean-Paul Dupont
}

\section{To cite this version:}

A Soueid Ahmed, Abderrahim Jardani, A Revil, Jean-Paul Dupont. Joint inversion of hydraulic head and self-potential data associated with harmonic pumping tests. Water Resources Research, 2016, 52 (9), pp.6769-6791. 10.1002/2016wr019058 . hal-01742266

\section{HAL Id: hal-01742266 \\ https://hal-normandie-univ.archives-ouvertes.fr/hal-01742266}

Submitted on 20 May 2021

HAL is a multi-disciplinary open access archive for the deposit and dissemination of scientific research documents, whether they are published or not. The documents may come from teaching and research institutions in France or abroad, or from public or private research centers.
L'archive ouverte pluridisciplinaire HAL, est destinée au dépôt et à la diffusion de documents scientifiques de niveau recherche, publiés ou non, émanant des établissements d'enseignement et de recherche français ou étrangers, des laboratoires publics ou privés. 


\section{Water Resources Research}

\section{RESEARCH ARTICLE \\ 10.1002/2016WR019058 \\ Joint inversion of hydraulic head and self-potential data associated with harmonic pumping tests}

Key Points:

- The self-potential method improves the results of harmonic hydraulic tomography

- Large-scale tomography of the hydraulic parameters is performed

- Large-scale inversion techniques help reducing significantly the

computational effort

Supporting Information:

- Supporting Information S1

- Data Set S1

- Data Set S2

- Data Set S3

Correspondence to:

A. Soueid Ahmed,

abdellahii@yahoo.com

Citation:

Soueid Ahmed, A., A. Jardani, A. Revil, and J. P. Dupont (2016), Joint inversion of hydraulic head and self-potential data associated with harmonic pumping tests, Water Resour. Res., 52, 6769-6791, doi:10.1002/

2016WR019058.

Received 12 APR 2016

Accepted 18 AUG 2016

Accepted article online 24 AUG 2016

Published online 9 SEP 2016 (c) 2016. American Geophysical Union. All Rights Reserved.

\author{
A. Soueid Ahmed1, A. Jardani1, A. Revil2, and J. P. Dupont1 \\ ${ }^{1}$ Université de Rouen, M2C, UMR 6143, CNRS, Morphodynamique Continentale et Côtière, Mont Saint Aignan, France, \\ ${ }^{2}$ ISTerre, CNRS, UMR 5275, Equipe Géophysique des Volcans, Université Savoie Mont-Blanc, 73376 cedex, Le Bourget du \\ Lac, France
}

\begin{abstract}
Harmonic pumping tests consist in stimulating an aquifer by the means of hydraulic stimulations at some discrete frequencies. The inverse problem consisting in retrieving the hydraulic properties is inherently ill posed and is usually underdetermined when considering the number of well head data available in field conditions. To better constrain this inverse problem, we add self-potential data recorded at the ground surface to the head data. The self-potential method is a passive geophysical method. Its signals are generated by the groundwater flow through an electrokinetic coupling. We showed using a 3-D saturated unconfined synthetic aquifer that the self-potential method significantly improves the results of the harmonic hydraulic tomography. The hydroelectric forward problem is obtained by solving first the Richards equation, describing the groundwater flow, and then using the result in an electrical Poisson equation describing the self-potential problem. The joint inversion problem is solved using a reduction model based on the principal component geostatistical approach. In this method, the large prior covariance matrix is truncated and replaced by its low-rank approximation, allowing thus for notable computational time and storage savings. Three test cases are studied, to assess the validity of our approach. In the first test, we show that when the number of harmonic stimulations is low, combining the harmonic hydraulic and selfpotential data does not improve the inversion results. In the second test where enough harmonic stimulations are performed, a significant improvement of the hydraulic parameters is observed. In the last synthetic test, we show that the electrical conductivity field required to invert the self-potential data can be determined with enough accuracy using an electrical resistivity tomography survey using the same electrodes configuration as used for the self-potential investigation.
\end{abstract}

\section{Introduction}

Estimating the spatial distributions of the subsurface hydraulic parameters (hydraulic conductivity and specific storage) by combining hydrological and geophysical data remains a challenging problem in the realm of hydrogeophysics (see a recent review by Binley et al. [2015]). In fact, knowledge of such parameters is of great interest in a variety of areas including contaminant transport, hydrogeological modeling, groundwater resources management, civil engineering, and petroleum engineering. Generally, the hydraulic parameters are estimated from the joint analysis in an inverse model, of a set of data possibly of different nature such as, for instance, hydraulic head, concentration history, and geophysical data [e.g., Chen et al., 2001; Pollock and Cirpka, 2010; Revil et al., 2012].

One classical way to cope against the ill-posedness of the inverse problem is the use of regularization techniques and then using a deterministic or stochastic algorithm to solve the inverse problem [e.g., Tikhonov and Arsenin, 1977; Vogel, 2002; Fu and Gomez-Hernandez, 2009]. An example of a regularization based on deterministic inverse approach is the quasi-linear geostatistical approach [Kitanidis, 1995, 1996]. This approach has been used in a broad range of studies [e.g., Cirpka and Kitanidis, 2000; Michalak and Kitanidis, 2004; Michalak et al., 2004; Li et al., 2005; Hirsch et al., 2006; Fienen et al., 2008; Cardiff and Barrash, 2011; Cardiff et al., 2012; Pollock and Cirpka, 2010; Soueid Ahmed et al., 2014, 2015, 2016]. Other geostatistical approaches such as the successive linear estimator (SLE) [e.g., Yeh et al., 1996] have also been used in different experiments of hydraulic tomography: (i) synthetic experiments [e.g., Yeh and Liu, 2000; Zhu and Yeh, 2005; Yeh and Zhu, 2007; Yeh et al., 2009; Sun et al., 2013], (ii) sandbox experiments [e.g., Liu et al., 2002; Liu 
et al., 2007; Illman et al., 2010], and (iii) field experiments [e.g., Straface et al., 2007; Illman et al., 2009; Berg and IIIman, 2011; Huang et al., 2011].

Recently, a new version of this quasi-linear geostatistical approach, which is more adapted to large-scale studies, has been introduced by Kitanidis and Lee [2014] and Lee and Kitanidis [2014]: the Principal Component Geostatistical Approach (PCGA). This method is matrix-free, which means that it does not compute the complete Jacobian matrix explicitly but only its matrix products. This allows for significant computational gains as the Jacobian matrix is computationally heavy to determine, especially when we are dealing with high numbers of measurements and model parameters. The PCGA also factorizes the prior covariance matrix into low-dimensional matrices using randomized algorithms [e.g., Halko et al., 2011]. The main information contained in the covariance matrix can be reported in its low-rank approximation. This approach allows for a significant storage advantage.

Harmonic hydraulic tomography (HHT) has been recently introduced as a potentially efficient method for characterizing subsurface hydraulic parameters [e.g., Cardiff et al., 2013]. It consists in using multiple frequencies harmonic excitations to stimulate the aquifer, collecting the responses of the aquifer, and interpreting it in an inverse framework. As the hydraulic and electric signals that we are dealing with are harmonics and can be mathematically represented by the sine and cosine functions, we believe that it is more appropriate to use the terminology "harmonic hydraulic tomography" instead of "oscillatory hydraulic tomography" that has been previously used in the literature. The main advantages of HHT include inter alia: (i) the absence of net injection or extraction of water. This can be convenient in contaminated sites (e.g., radioactive) where handling water extracted during pumping tests can be problematic. (ii) The induced stimulations are multifrequency harmonic; thus, they do have prior known frequencies and the measured signal can be separated from ambient noises by the mean of signal processing techniques. This is useful because even if the signal is highly corrupted with noise, it can be exploited very efficiently. (iii) Using multiple frequencies allows for fully exploring heterogeneities of the aquifer and better capturing it. (iv) In some areas like petroleum engineering, HHT can be performed without interrupting the oil production. The idea of using harmonic pumping tests for reservoir characterization first emerged in the petroleum sciences [e.g., Kuo, 1972; Hollaender et al., 2002; Ahn and Horne, 2010; Fokker et al., 2012]. In hydrogeology, Rasmussen et al. [2003] derived analytical solutions for harmonic pumping tests and used it to estimate the effective hydraulic parameters of the contaminated Savannah River site in USA. Fokker et al. [2013] successfully performed multifrequency harmonic pressure stimulations in the frequency domain to estimate the simplified permeability of a heterogeneous aquifer. The use of a frequency domain model gave them the possibility to significantly reduce the computational time required for solving the forward problem.

Cardiff et al. [2013] performed sensitivity analysis for multiple frequencies harmonic pumping tests and estimated the hydraulic conductivity of a synthetic aquifer using HHT combined with the geostatistical framework of Kitanidis [1995, 1996]. Bakhos et al. [2014] presented a least squares based technique to filter the sinusoidal signal associated with harmonic pumping tests and performed the joint inversion of storativity and hydraulic conductivity using HHT. Rabinovich et al. [2015] used harmonic pumping tests to estimate the effective storativity, specific yield, and hydraulic conductivity of the Boise Hydrogeophysical Research Site in USA.

The goal of the present work is to image the saturated specific storage $\left(S_{S}\right)$ and hydraulic conductivity $(K)$ fields by combining HHT and the self-potential (SP) method in a joint inversion problem. The mechanism by which the flow of the groundwater generates a measurable electrical field can be explained as follows. The minerals of a porous material composite are always coated by an electrical double layer because of the reactivity of the mineral surfaces in water and Coulombic interactions [Davis et al., 1978]. This double layer is formed by a Stern layer of weakly or strongly sorbed ions (the Stern layer) and a diffuse layer in which the ionic concentrations obey Poisson-Boltzmann statistics [Chapman, 1913]. The flow of the groundwater in porous media drags the electrical charges of the diffusive layer. This creates an electrical current density called the streaming current density, which is the source of an electrical field known as the streaming potential [e.g., Ahmad, 1969; Revil et al., 2003; Jardani et al., 2006]. The streaming potential can be measured in saturated or unsaturated conditions [e.g., Alkafeef et al., 2001; Vinogradov and Jackson, 2011; Revil and Mahardika, 2013].

The self-potential (SP) method is a passive geophysical method measuring the resulting electrical potential signatures at the ground surface or in wells. It consists in placing an array of nonpolarizable electrodes, 
connecting them to a multichannel voltmeter characterized by a high impedance $(>10 \mathrm{M} \Omega$ ) and a good sensitivity (typically $0.1 \mathrm{mV}$ ) and measuring the variations of the electrical potential over time. Then, the steaming potential signature of underground fluid movement is sampled over space and time. The SP method has been used in hydrogeophysics in a growing number of publications [Semenov, 1980; Rizzo et al., 2004; Titov et al., 2005; Suski et al., 2006; Jardani et al., 2006, 2009, 2013; Maineult et al., 2008; Malama et al., 2009a, 2009b; Revil and Mahardika, 2013; Ozaki et al., 2014; Soueid Ahmed et al., 2014, 2016; Chidichimo et al., 2015].

A more detailed compendium on the applications of the SP method in hydrogeology can be found in Revil and Jardani [2013]. Only two published papers dealt with the self-potential signals generated during harmonic pumping tests. Maineult et al. [2008] studied the self-potential signals generated during harmonic pumping tests performed in a field test aquifer in Germany. They pointed out the presence of a nonlinear behavior of the self-potential signals recorded at the ground surface and they owed it to saturation, desaturation processes occurring in the capillary fringe. Revil et al. [2008] modeled numerically using a finite element code these nonlinear effects using the Richards equation and incorporating hysteresis of the hydraulic conductivity and capillary pressure curves in the capillary fringe.

Our goal is to combine the self-potential and head measurements during HHT in a large-scale framework, to capture the 3-D spatially heterogeneities of aquifers. To the best of our knowledge such methodology has never been developed so far. Although we are working on synthetic models, we try to develop realistic scenarios. The main progresses made during the current work compared to the previous work of ours [Soueid Ahmed et al., 2016] include the use of an efficient large-scale inversion approach, combining the HHT and the SP method, performing an electrical resistivity tomography (ERT) survey to independently obtain the electrical conductivity spatial distribution which is required in our methodology, and using some signal processing tools to filter the simulated hydraulic and streaming potential signals as in real field applications.

\section{Constitutive and Field Equations}

This section presents the constitutive and field equations that need to be solved to perform the forward modeling of the hydraulic heads and self-potential signatures. As the self-potential distribution is generated by the groundwater flow, the forward modeling lies on solving first the groundwater flow problem. Assuming that water is the wetting phase, the groundwater flow in a variably unsaturated, isotropic porous medium is governed by the Richards equation [Richards, 1931]

$$
\left(C+S_{w} S_{S}\right) \frac{\partial h}{\partial t}-\nabla \cdot\left(K_{r}\left(S_{w}\right) K \nabla h\right)=q
$$

where $C$ is the specific moisture capacity $\left(\mathrm{m}^{-1}\right)$ and can be determined using laboratory experiments, $S_{w}$ is the water saturation (when the porous body is fully water-saturated, $\left.S_{w}=1\right), S_{s}$ is the specific storage $\left(\mathrm{m}^{-1}\right)$, $h$ is the hydraulic head $(\mathrm{m}), t$ is the time $(\mathrm{s}), K_{r}$ denotes the relative hydraulic conductivity (dimensionless), $K$ is the saturated hydraulic conductivity $\left(\mathrm{m} \mathrm{s}^{-1}\right)$, and $q$ is the sink term representing any external sources of water $\left(\mathrm{s}^{-1}\right)$. The air pressure is assumed to be constant. This is a key assumption when considering unsaturated flow by comparison with solving a two-phase flow problem. The use of the Richards equation in hydraulic tomography analysis is not easy and only few works have been conducted within this context [e.g., Mao et al., 2013; Zhao et al., 2015, and references therein].

Note that equation (1) reduces to the correct flow equation in saturated conditions and can be therefore used to represent both saturated and unsaturated flow. In the present simulations we will keep the saturation levels close to full saturations to focus our discussion on linear effects (see Revil et al. [2008] for a discussion of nonlinear effects).

Equation (1) is subject to the following initial and boundary conditions:

$$
\begin{gathered}
h=h_{0} \text { at } t=0, \\
h=h_{D} \text { on } \Gamma=\Gamma_{D},
\end{gathered}
$$




$$
-\boldsymbol{n} . K \nabla h=0 \text { on } \Gamma=\Gamma_{N},
$$

where $h_{0}$ is the initial head $(\mathrm{m}), h_{D}$ is the imposed hydraulic head $(\mathrm{m}), \Gamma$ represents the boundaries of the simulation domain, $\Gamma_{D}$ enotes the Dirichlet boundaries, $\Gamma_{N}$ denotes the Neumann boundaries, and $\boldsymbol{n}$ is the outward unit vector normal to $\Gamma_{N}$.

In this study, we used a harmonic pumping source defined by the expression below

$$
q(\boldsymbol{x}, t)=q_{0} \cos (\omega t)\left(1-\exp \left(-(t / T)^{2}\right)\right) \delta\left(\mathbf{x}-\mathbf{x}_{q}\right),
$$

where $q_{0}$ is a constant corresponding to the peak of the volume flow rate $\left(s^{-1}\right), \omega$ is the angular frequency (in rad $\mathrm{s}^{-1}$ ), $T$ is the period (s), $\delta$ is the Dirac distribution, $\boldsymbol{x}$ denotes the 3-D spatial coordinates, and $\boldsymbol{x}_{q}$ denotes the location where the harmonic stimulation is applied. The saturation degree $S_{w}$ and the relative hydraulic conductivity $K_{r}$ can be parameterized using a variety of models involving or not hysteresis and the history of flow saturation/desaturation processes. We chose in this paper the van Genuchten model to parameterize these two parameters as a function of the saturation [van Genuchten, 1980]:

$$
\begin{gathered}
S_{e}=\frac{1}{\left(1+|\alpha \psi|^{n}\right)^{m}}, \\
K_{r}=S_{e}\left(1-\left(1-S_{e}^{1 / m}\right)^{m}\right)^{2}, \\
C=\left(\frac{\alpha m}{1-m}\right)\left(S_{w}-S_{w r}\right) S_{e}^{1 / m}\left(1-S_{e}^{1 / m}\right)^{m},
\end{gathered}
$$

where $S_{e}$ is the effective water saturation (dimensionless), $\psi=h / \rho g$ denotes the capillary pressure head $(\mathrm{m}), \rho$ is the water density $\left(1000 \mathrm{~kg} \mathrm{~m}^{-3}\right), g$ denotes the acceleration of gravity $\left(9.8 \mathrm{~m} \mathrm{~s}^{-2}\right), m, n$, and $/$ are constants characterizing the pore network (we use $m=1-1 / n$ [see van Genuchten, 1980], and $\alpha$ is related to the capillary entry pressure.

The water saturation (dimensionless) is related to the effective water saturation $S_{e}$ by

$$
S_{e}=\frac{S_{w}-S_{w r}}{1-S_{w r}}
$$

where $S_{w r}$ denotes the residual water saturation. Note also that we have neglected inertial effects corresponding to high Reynolds numbers (i.e., Re $>1$ ). The inertial effect in the local Navier-Stokes equation at the local scale is responsible for an apparent hydraulic conductivity that is frequency-dependent in the Richards equation [see Revil and Mahardika, 2013, and references therein]. However, these effects are not expected to be seen below $100 \mathrm{~Hz}$.

Equation (1) can be solved using a numerical method. We used a finite element package (Comsol Multiphysics) to solve it. Assuming that the electro-osmotic contribution in the Darcy velocity is negligible compared to the contribution of the hydraulic gradient (see details in Revil et al. [1999]) and neglecting inertial effects, the flow velocity is given by the classical Darcy law

$$
\boldsymbol{u}=-K_{r}\left(S_{w}\right) K \nabla h .
$$

We now present governing equations for the self-potential field. The total flux of electrical charges in a medium is represented by the current density $\boldsymbol{j}\left(\mathrm{A} \mathrm{m}^{-2}\right)$ defined as follows [e.g., Sill, 1983; Jardani et al., 2007]:

$$
\boldsymbol{j}=-\sigma\left(S_{w}\right) \nabla \varphi+\frac{\hat{Q}_{v} \boldsymbol{u}}{S_{w}},
$$

where $\sigma\left(S_{w}\right)$ is the electrical conductivity of the partially saturated porous media $\left(\mathrm{S} \mathrm{m}^{-1}\right)$ with $\sigma\left(S_{w}\right)=$ $\sigma_{\text {sat }} S_{w}^{n}$ where $\sigma_{\text {sat }}$ is the electrical conductivity of the porous medium at full saturation, $\varphi$ is the selfpotential $(V)$, and $\hat{Q}_{V}$ (in $\mathrm{C} \mathrm{m}^{-3}$ ) is an effective charge density at saturation. This parameter $\hat{Q}_{V}$ represents the effective excess charge density per unit pore volume that is dragged by the flow of the pore water at saturation. It can be inferred from the intrinsic permeability at saturation $k\left(\mathrm{~m}^{2}\right)$ using Jardani et al. [2007] relationship: 


$$
\hat{Q}_{V}=-9.2-0.82 \log _{10} k
$$

where the permeability at saturation $k$ is related to the hydraulic conductivity $K$ by $K=k \rho_{f} g / \eta_{f}$, where $\rho_{f}$ and $\eta_{f}$ denote the mass density and dynamic viscosity of the pore water. Equation (12) seems to be independent of the material used and scale of investigation [Revil and Mahardika, 2013]. Equation (11) can be seen as a generalized Ohm's law.

The continuity equation for electrical charges [Sill, 1983] states that $\nabla \cdot \boldsymbol{j}=0$ in the low-frequency limit of the Maxwell equation for which we can neglect the time derivatives of the various fields. Combining this conservation equation with the constitutive equation given by equation (11), we obtain a Poisson equation of the self-potential field $\varphi$

$$
\nabla \cdot(\sigma \nabla \varphi)=\nabla \cdot\left(\hat{Q}_{V} \boldsymbol{u} / S_{w}\right)
$$

The right-hand side of equation (13) is a source term associated with the flow of the pore water. Equation (13) is subject to the following boundary conditions:

$$
\begin{gathered}
\varphi=0 \text { on } \Gamma=\Gamma_{D}, \\
-\boldsymbol{n} \cdot\left[\sigma \nabla \varphi-\hat{Q}_{V} \boldsymbol{u} / S_{w}\right]=0 \text { on } \Gamma=\Gamma_{N} .
\end{gathered}
$$

We have now provided all the equations needed to forward model the groundwater flow and the resulting electrical field problem. We can move to the description of the inverse problem in the next section.

\section{Inverse Modeling}

The estimation of the hydraulic parameters fields (hydraulic conductivity and specific storage) can be formulated as a joint inverse problem. The solution of this inverse problem constitutes the best set of parameters meeting the defined convergence criteria. This parameter estimation can be written as a minimization problem. The classical Geostatistical Approach (GA) seeks to obtain the best set of parameters that minimizes the following objective function:

$$
L(\mathbf{s})=\frac{1}{2}(\mathbf{d}-F(\mathbf{s}))^{T} \mathbf{V}^{-1}(\mathbf{d}-F(\mathbf{s}))+\frac{1}{2}(\mathbf{s}-\mathbf{X} \beta)^{T} \mathbf{Q}^{-1}(\mathbf{s}-\mathbf{X} \beta),
$$

in which $s$ is the $m_{s} \times 1$ vector of model parameters (e.g., the logarithms of the hydraulic parameter unknowns for $m_{s}$ cells, i.e., $m_{s}$ describes the number of unknowns), $\mathbf{d}$ denotes the $n_{d} \times 1$ vector of observed data (hydraulic head and/or self-potential data, $n_{d}$ is the number of measurements), $\mathbf{V}$ is the $n_{d} \times n_{d}$ covariance matrix of data errors, $F($.$) is the forward problem operator (in our case, it is represented by the$ Richards and Poisson equations), $\mathbf{X}$ is an $m_{s} \times p$ vector (in our case, $p=2$ ), $\beta$ denotes the $p \times 1$ drift coefficient vector, and $\mathbf{Q}$ is the $m_{s} \times m_{s}$ spatial covariance matrix. This matrix $\mathbf{Q}$ is represented by a variogram and it gives information about how the hydraulic parameters are spatially distributed. In this this study, we chose a Gaussian variogram and we assume that its properties (variance and correlation length) are unknown and shall be estimated as well. Once the objective function value became almost unchanged through the iterative process, the convergence has been reached. Such objective function (equation (16)) is used to gauge the errors between observed and simulated data under the restriction of finding a physically meaningful solution.

The GA uses an iterative process to estimate the best set of parameters, by linearizing the quantity $F(\mathbf{s})$ using first-order Taylor-series as follows:

$$
F(\mathbf{s})=F\left(\tilde{\mathbf{s}}_{i}\right)+\mathbf{J}_{i}\left(\mathbf{s}-\tilde{\boldsymbol{s}}_{i}\right),
$$

where $\tilde{\boldsymbol{s}}_{i}$ is the current best parameters set computed at iteration i of the iterative process, $\boldsymbol{J}_{i}$ is the $n_{d} \times m_{s}$ sensitivity matrix of the measurements with respect to the model parameters $\tilde{\boldsymbol{s}}_{i}$,

$$
\mathbf{J}_{i}=\left.\frac{\partial F(\boldsymbol{s})}{\partial \mathbf{s}}\right|_{\mathbf{s}=\tilde{\boldsymbol{s}}_{i}} .
$$

The solution is then updated according to 


$$
\tilde{\boldsymbol{s}}_{i+1}=\mathbf{X} \beta_{i+1}+\mathbf{Q} \mathbf{J}_{i}^{T} \xi_{i+1},
$$

where $\beta_{i+1}$ and $\xi_{i+1}$ are obtained by solving the following linear system:

$$
\left(\begin{array}{cc}
\mathbf{J}_{i} \mathbf{Q} \mathbf{J}_{i}^{T}+\mathbf{V} & \mathbf{J}_{i} \mathbf{X} \\
\left(\mathbf{J}_{i} \mathbf{X}\right)^{T} & \mathbf{0}
\end{array}\right)\left(\begin{array}{c}
\beta_{i+1} \\
\xi_{i+1}
\end{array}\right)=\left(\begin{array}{c}
\mathbf{d}-F\left(\boldsymbol{s}_{i}\right)+\mathbf{J}_{i} \boldsymbol{s}_{i} \\
0
\end{array}\right) .
$$

From here, the main drawbacks of the GA become quite visible. In fact, the evaluation and the storage of the sensitivity matrix $\mathbf{J}$ is very computationally demanding. Usually, this matrix is computed using the finite differences method or the adjoint state method, with both methods, several runs of the forward and/or adjoint operator are needed, according to the number of unknowns and measurements. In real field conditions, the unknowns and measurements can number millions-this makes the computation and storage of such large dense matrix infeasible in practice. Furthermore, the construction of $\mathbf{J Q} \mathbf{J}^{T}, \mathbf{J X}, \mathbf{J} \mathbf{J}, \mathbf{J Q}$, and $\mathbf{Q} \mathbf{J}^{T}$ will arise a grand storage challenge as the spatial covariance matrix $\mathbf{Q}$ can be even larger than $\mathbf{J}$.

An efficient and convenient way to get around all the aforementioned drawbacks of the GA is to avoid the explicit construction of $\mathbf{J}$ and to reduce the dimensionality of the inverse problem by only keeping in $\mathbf{Q}$ the components that contain the major information about the heterogeneities of the medium. For that sake, the PCGA was recently developed [e.g., Kitanidis and Lee, 2014; Lee and Kitanidis, 2014].

In PCGA, we replace $\mathbf{Q}$ by a low-rank approximation, for example, truncated eigenvalue decomposition:

$$
\mathbf{Q} \approx \mathbf{Q}_{\tilde{K}}=\mathbf{P}_{\tilde{K}} \mathbf{D}_{\tilde{K}} \mathbf{P}_{\tilde{K}}^{T}=\sum_{i=1}^{\tilde{K}} \varsigma_{i} \varsigma_{i}^{T},
$$

with

$$
\varsigma_{i}=\sqrt{\left|\lambda_{i}\right|} \mathbf{P}_{i}
$$

where $\tilde{K}$ is the truncation order, $\mathbf{D}$ is the $\tilde{K} \times \tilde{K}$ diagonal matrix of eigenvalues, $\mathbf{P}$ is a $\tilde{K} \times n_{d}$ matrix composed of eigenvectors (organized on the columns of $\mathbf{P}$ ), and $\lambda_{i}$ is the ith eigenvalue of $\mathbf{Q}_{\tilde{K}}$. The choice of $\tilde{K}$ is important in PCGA. It should be moderate to ensure computational and storage savings but it should not cut off some important information that can be stored in $\mathbf{Q}$.

Several methods can be used to choose $\tilde{K}$. For example, one can use a trial-and-error process to select optimum $\tilde{K}$, one method is to launch the PCGA with small values of $\tilde{K}$ and then use the obtained model as initial model for new simulations launched with greater $\tilde{K}$. Another alternative reported in Lee and Kitanidis [2014] is to choose $\tilde{K}$ such as $\left\|\mathbf{Q}-\mathbf{Q}_{\tilde{K}}\right\| \ll 1$.

The matrix $\mathbf{J}$ is not explicitly computed, only its products are evaluated as follows:

$$
\begin{aligned}
\mathbf{J} \mathbf{s} & \approx \frac{1}{\delta}[F(\mathbf{s}+\delta \mathbf{s})-F(\mathbf{s})], \\
\mathbf{J} \mathbf{X}_{i} & \approx \frac{1}{\delta}\left[F\left(\mathbf{s}+\delta \mathbf{X}_{i}\right)-F(\mathbf{s})\right],
\end{aligned}
$$

where $\mathbf{X}_{i}$ is the ith column of $\mathbf{X}$ and $\delta$ is the finite differences step that can be chosen empirically or computed according to [Lee and Kitanidis, 2014].

where

$$
\mathbf{J} \mathbf{Q} \mathbf{J Q}_{\tilde{K}}=\mathbf{J} \sum_{i=1}^{\tilde{K}} \varsigma_{i} \varsigma_{i}{ }^{\top}=\sum_{i=1}^{\tilde{K}}\left(\mathbf{J}_{\varsigma_{i}}\right) \varsigma_{i}{ }^{\top} \approx \sum_{i=1}^{\tilde{K}} v_{i} \varsigma_{i}{ }^{T},
$$

$$
\begin{gathered}
v_{i}=\mathbf{J}_{\varsigma_{i}} \approx \frac{1}{\delta}\left[F\left(\boldsymbol{s}+\delta \varsigma_{i}\right)-F(\mathbf{s})\right], \\
\mathbf{J Q J}^{T} \approx \mathbf{J} \mathbf{Q}_{\tilde{K}} \mathbf{J}^{T}=\sum_{i=1}^{\tilde{K}}\left(\mathbf{J}_{\varsigma_{i}}\right)\left(\mathbf{J}_{\varsigma_{i}}\right)^{T} \approx \sum_{i=1}^{\tilde{K}} v_{i} v_{i}{ }^{T},
\end{gathered}
$$

The product in equation (23) requires two forward problem runs, equation (24) requires $p$ forwards runs, while equations (24) and (25) require $\tilde{K}$. This result in a total of $2+p+\tilde{K}$ forward problem evaluations in 


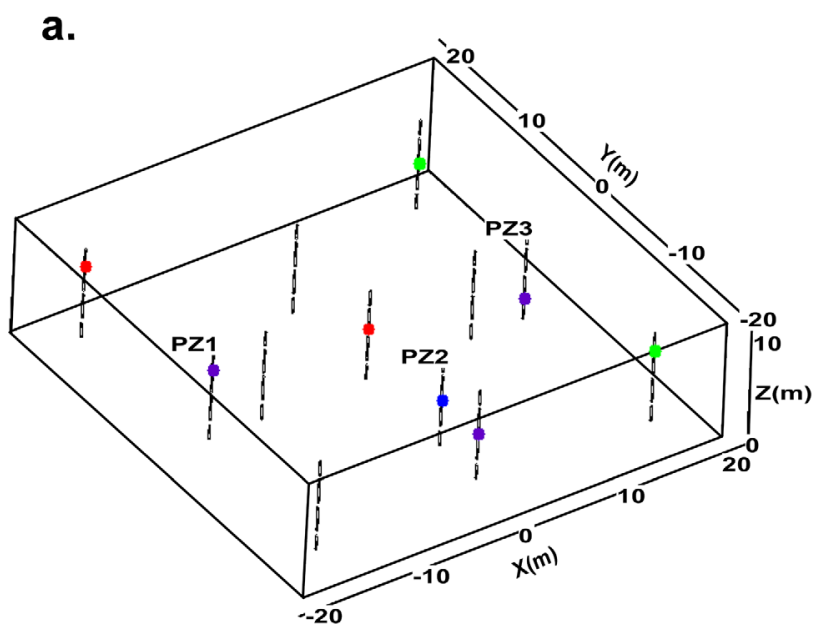

b.

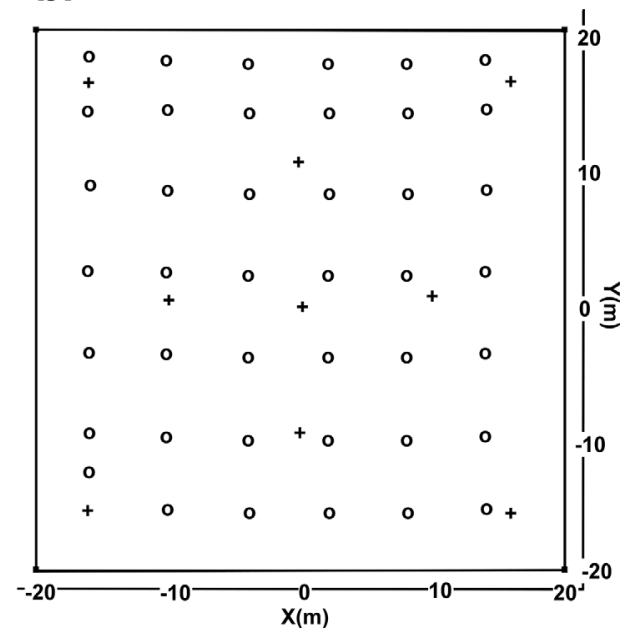

Figure 1. Description of the aquifer geometry. (a) Three-dimensional view of the aquifer. The synthetic aquifer is covered by 12 wells. Each well has three ports located at different depths: 7.5, 5, and $2.5 \mathrm{~m}$. The colors denote the pumping stimulations that are used for generating the harmonic signals. Thus, multiple frequencies can be used during one harmonic

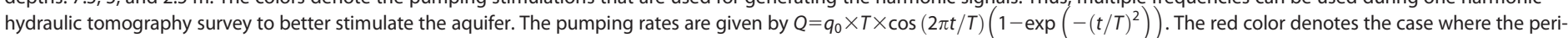

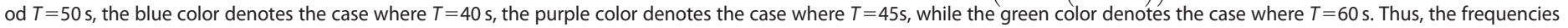
that we used are $1 / 40,1 / 45,1 / 50$, and $1 / 60 \mathrm{~Hz}$. Three of the wells, i.e., PZ1, PZ2 and PZ3, are not utilized during the inversion. We use them for performing a series of three cross-validation pumping tests during which the pumping rate and the pumping area are represented by the purple dots. (b). Two-dimensional view of the aquifer. The cross signs represent the locations of the wells. The black open circles represent the location of the 30 nonpolarizing electrodes used to record the self-potential anomalies as well as the electrical potential field generated while performing the electrical resistivity tomography. The electrodes are placed $40 \mathrm{~cm}$ below the ground surface.

each iteration. Taking into account that $\tilde{K} \ll m_{s}, n_{d}$, this constitutes indeed a drastic computational benefit compared to computing the Jacobian matrix using the classical GA, because the latter requires $n_{d}+1$ adjoint runs when combined to the adjoint state method and $m_{s}+1$ runs when combined to the finite differences method.

One can take advantage of the PCGA to compute more economic objective function:

$$
L(\mathbf{s}) \approx \frac{1}{2}(\mathbf{d}-F(\mathbf{s}))^{T} \mathbf{R}^{-1}(\mathbf{d}-F(\mathbf{s}))+\frac{1}{2} \boldsymbol{s}^{T} \mathbf{P D}^{-1} \mathbf{P}^{T} \boldsymbol{s}
$$

where the second term only require $O\left(\tilde{K} m_{s}\right)$ multiplications.

To summarize, the PCGA can be described in the following steps:

1. Compute $\mathbf{Q}_{\tilde{k}}$, the low-rank approximation of $\mathbf{Q}$.

2. Compute the $\mathbf{J}_{i}$ products: $\mathbf{J}_{i} \mathbf{X}, \mathbf{J}_{i} \mathbf{Q} \mathbf{J}_{i}{ }^{T}, \mathbf{J}_{i} \mathbf{Q}$.

3. Solve the linear system

$$
\left[\begin{array}{cc}
\mathbf{J}_{i} \mathbf{Q} \mathbf{J}_{i}^{T}+\boldsymbol{V} & \mathbf{J}_{i} \mathbf{X} \\
\left(\mathbf{J}_{i} \mathbf{X}\right)^{T} & \mathbf{0}
\end{array}\right]\left[\begin{array}{c}
\mathbf{A}^{T} \\
\mathbf{B}
\end{array}\right]=\left[\begin{array}{c}
\mathbf{J}_{i} \mathbf{Q} \\
\mathbf{X}^{T}
\end{array}\right]
$$

4. Update the solution $\boldsymbol{s}_{i+1}$ as

$$
\boldsymbol{s}_{i+1}=\mathbf{A}\left(\mathbf{d}-F\left(\boldsymbol{s}_{i}\right)+\mathbf{J} \boldsymbol{s}_{i}\right)
$$

\section{Numerical Experiments}

We now explore how adding the self-potential data can improve the tomography of the hydraulic parameters obtained while performing a series of harmonic pumping tests. Three numerical experiments are performed to point out the benefit of using the self-potential data in addition to the head data.

In the first experiment, we use one single pumping port to perform HHT alone, and then we combine it with a self-potential survey in which the same pumping port is used as self-potential signal generator. In the second experiment, we increase the number of harmonic stimulations as well as the frequencies and we estimate the hydraulic parameters using hydraulic head data alone, then the self-potential data alone, 

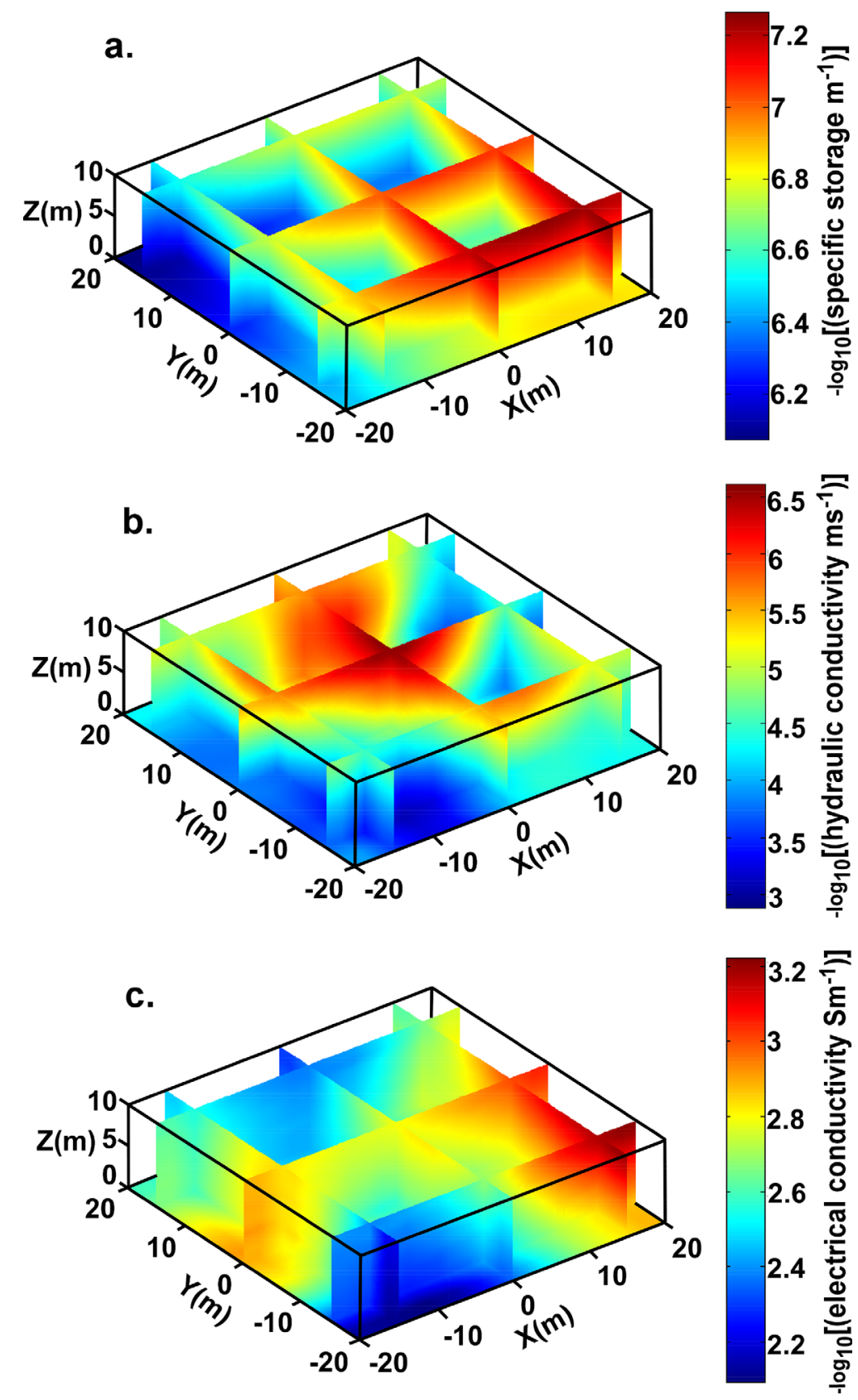

Figure 2. True synthetic field parameters. (a). True distribution of the specific storage field. (b) True distribution of the hydraulic conductivity field in the aquifer. (c) True electrical conductivity field. All the fields were generated using the SGEMS geostatistical software. During all the experiments, the specific storage and hydraulic conductivity are simultaneously estimated. The electrical conductivity field was assumed to be perfectly known during Experiments 1 and 2, while it is estimated during the third experiment by the means of an electrical resistivity tomography using the same electrodes pattern than for self-potential.

and then using the joint inversion of both sets of data. As our approach requires the knowledge of the electrical conductivity field, we assume in the third and last numerical experiment that the electrical conductivity field is unknown; thus, we perform synthetic ERT survey to estimate this field and we use the result in the simultaneous reconstruction of the hydraulic parameters from the joint inversion of harmonic hydraulic head and self-potential data. Even though we are using the Richards equation which takes into account the saturated as well as the unsaturated zones, all our experiments are performed under fully saturated conditions. We will first describe in the next section the synthetic aquifer used for these experiments. 


\begin{tabular}{|c|c|c|}
\hline Dimension & \multicolumn{2}{|c|}{$3-D$} \\
\hline Domain of interest & \multicolumn{2}{|c|}{$40 m \times 40 m \times 10 m$} \\
\hline Number of unknowns & \multicolumn{2}{|c|}{1000 for each parameter } \\
\hline Number of nodes & \multicolumn{2}{|c|}{13,124} \\
\hline Simulation time & \multicolumn{2}{|c|}{$30 \mathrm{~min}$} \\
\hline Measurement times & \multicolumn{2}{|c|}{$20,21, \ldots, 30 \mathrm{~min}$} \\
\hline Number of wells & \multicolumn{2}{|c|}{12} \\
\hline Number of electrodes & \multicolumn{2}{|c|}{30} \\
\hline \multirow[t]{7}{*}{ Number of measurements } & \multirow[t]{3}{*}{ Experiment 1} & HHT 286 \\
\hline & & SP 473 \\
\hline & & Joint 759 \\
\hline & \multirow[t]{3}{*}{ Experiments 2 and 3} & HHT 1430 \\
\hline & & SP 2365 \\
\hline & & Joint 3795 \\
\hline & \multicolumn{2}{|c|}{ ERT 205} \\
\hline \multirow{3}{*}{$\begin{array}{l}\text { Variograms kernels for } \\
\text { true parameters }\end{array}$} & \multirow{3}{*}{\multicolumn{2}{|c|}{$\begin{array}{l}S_{s} \text { field } q\left(x, x^{\prime}\right)=\exp \left(-\left|x-x^{\prime}\right|^{2} / 18^{2}\right) \\
K \text { field } q\left(x, x^{\prime}\right)=\exp \left(-\left|x-x^{\prime}\right|^{2} / 10^{2}\right) \\
\sigma \text { field } q\left(x, x^{\prime}\right)=\exp \left(-\left|x-x^{\prime}\right|^{2} / 15^{2}\right)\end{array}$}} \\
\hline & & \\
\hline & & \\
\hline Truncation order $\tilde{K}$ & \multicolumn{2}{|c|}{25} \\
\hline Van Genutchen parameters & \multicolumn{2}{|l|}{$m=1.5, n=2, I=1 / 2$} \\
\hline
\end{tabular}
aforementioned domain of interest is enclosed within a larger homogenous buffer domain to attenuate the effects of boundary conditions on the hydraulic and electric signals. Synthetic hydraulic parameters and electrical conductivity fields were generated using the geostatistical software SGEMS [Deutsch and Journel, 1992]. These fields were independently generated and are uncorrelated. The $S_{S}$ values are between $10^{-7.2}$ and $10^{-6} \mathrm{~m}^{-1}$. The $K$ values are between $10^{-6.6}$ and $10^{-2.8} \mathrm{~m} \mathrm{~s}^{-1}$ while the electrical conductivity values are in the range $10^{-3.2}-10^{-2} \mathrm{~S} \mathrm{~m}^{-1}$ (Figure 2). Such fields are typically representative of unconfined sandy alluvial aquifers [e.g., Domenico and Mifflin, 1965; Sneed, 2001]. We use Gaussian variograms to generate such fields, we suppose that the properties of these variograms are unknown and we estimate them through experimental variograms using the approach reported in Schwanghart [2008].

For all the experiments studied in this work, no hydraulic flux boundary conditions are assigned to top and bottom sides of the domain while null hydraulic head boundary conditions are assigned to remaining sides. For the self-potential problem, insulation boundary conditions are assigned to the top and bottom boundaries while zero potential conditions are fixed on the remaining boundaries. The simulation time lasts 30 min with measurements recorded each minute. The $S_{s}, K$ and electrical conductivity $\sigma$ fields are discretized into vectors containing 1000 elements for each property. All the relevant information regarding the synthetic field and the true parameters are reported in Table 1.

An initial hydraulic head of $3.5 \mathrm{~m}$ is assigned to the domain of simulation. We first do some forward modeling to illustrate the behavior of the self-potential signals. We solve the hydroelectric problem using the true parameters shown in Figure 2 as inputs parameters. Figure 3 shows the resulting self-potential distributions for different measurement times. One can notice that the self-potential distributions magnitudes vary with the harmonic fluctuations of the pumping, and are also influenced by the heterogeneities of the hydraulic parameters, suggesting that it can reveal some interesting information about these heterogeneities. An issue that can be observed when performing harmonic pumping tests is the relative weakness of the hydraulic head and self-potential perturbations induced by the stimulations. One can wonder if these signals can be still workable if they are corrupted with too much disturbances. To address this issue, we used some powerful signal processing techniques [e.g., Toll and Rasmussen, 2007; Bakhos et al., 2014] to isolate the signal from the surrounding noises.

We consider that our measured signal is composed of sinusoids with a known frequency $\omega$ and an error term $e$

$$
\bar{y}(x, \mathbf{t})=\alpha \cos (\omega \mathbf{t})+\beta \sin (\omega \mathbf{t})+e,
$$

where $\bar{y}$ denote the hydraulic head or self-potential time series, $\mathbf{t}=\left[t_{1}, t_{2}, \cdots, t_{d}\right]$ is the vector of measurement times, $\alpha$ and $\beta$ are the cosinusoidal and sinusoidal coefficients, respectively. 
a.

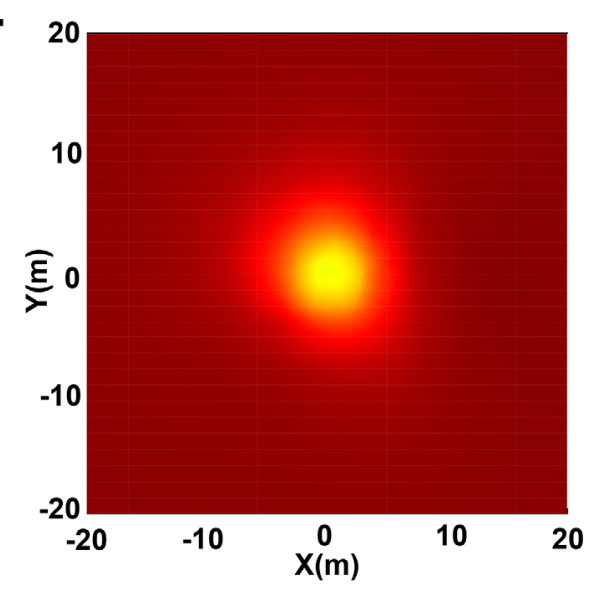

b.
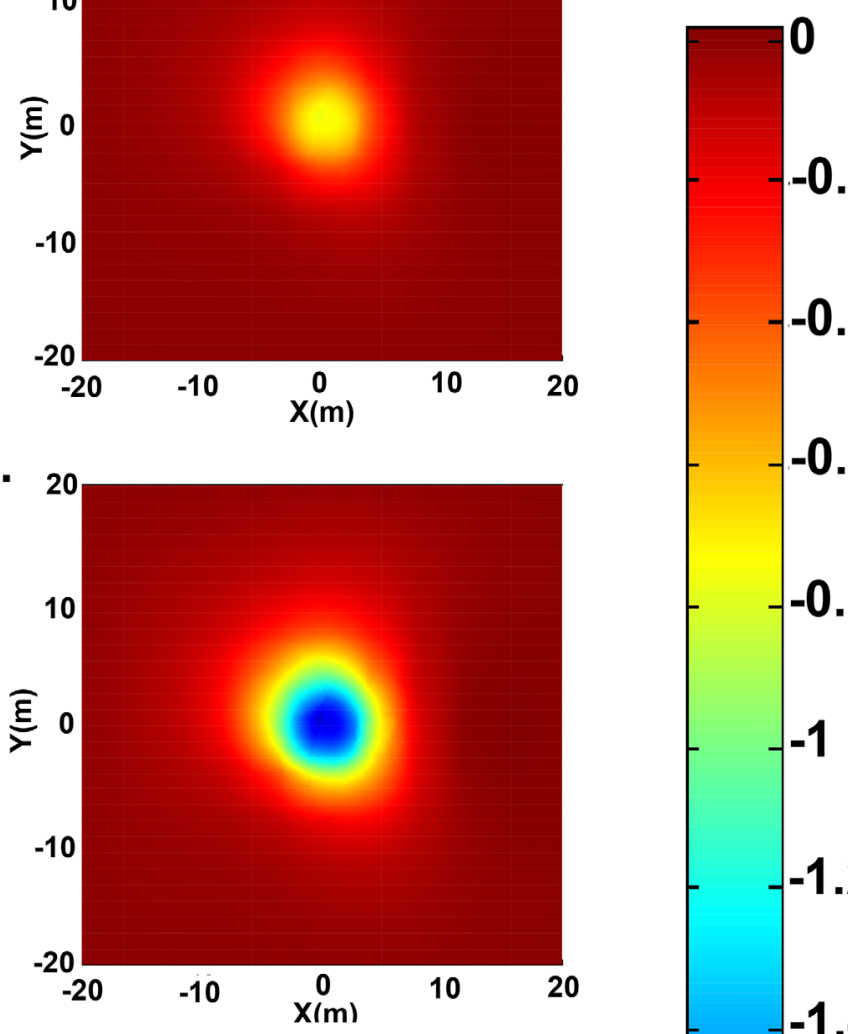

c.

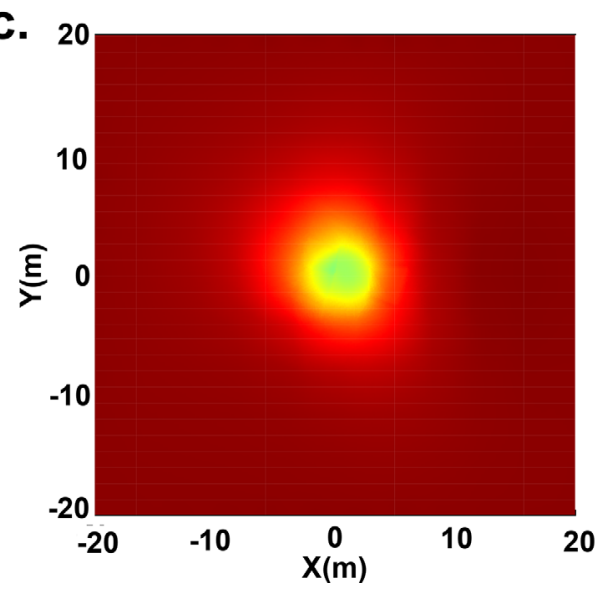

$-1.6$

$-1.8$

$-2$

Figure 3. Distributions of the self-potential field at the ground surface (top surface of the simulated domain). (a) Self-potential distribution at $t=100 \mathrm{~s}$. (b) Self-potential distribution at $t=150 \mathrm{~s}$. (c) Self-potential distribution at $t=200 \mathrm{~s}$. The maps are taken at the depth where the electrodes are placed, that is $40 \mathrm{~cm}$ below the ground surface. The self-potential maps clearly show the pumping areas as negative anomalies and the intensity of the self-potential signals fluctuate with the harmonic pumping intensity.

One can rewrite equation (31) in terms of matrices as

$$
\overline{\boldsymbol{y}}=\boldsymbol{C} \gamma+\mathrm{e},
$$

where

$$
\gamma=\left(\begin{array}{l}
\alpha \\
\beta
\end{array}\right),
$$



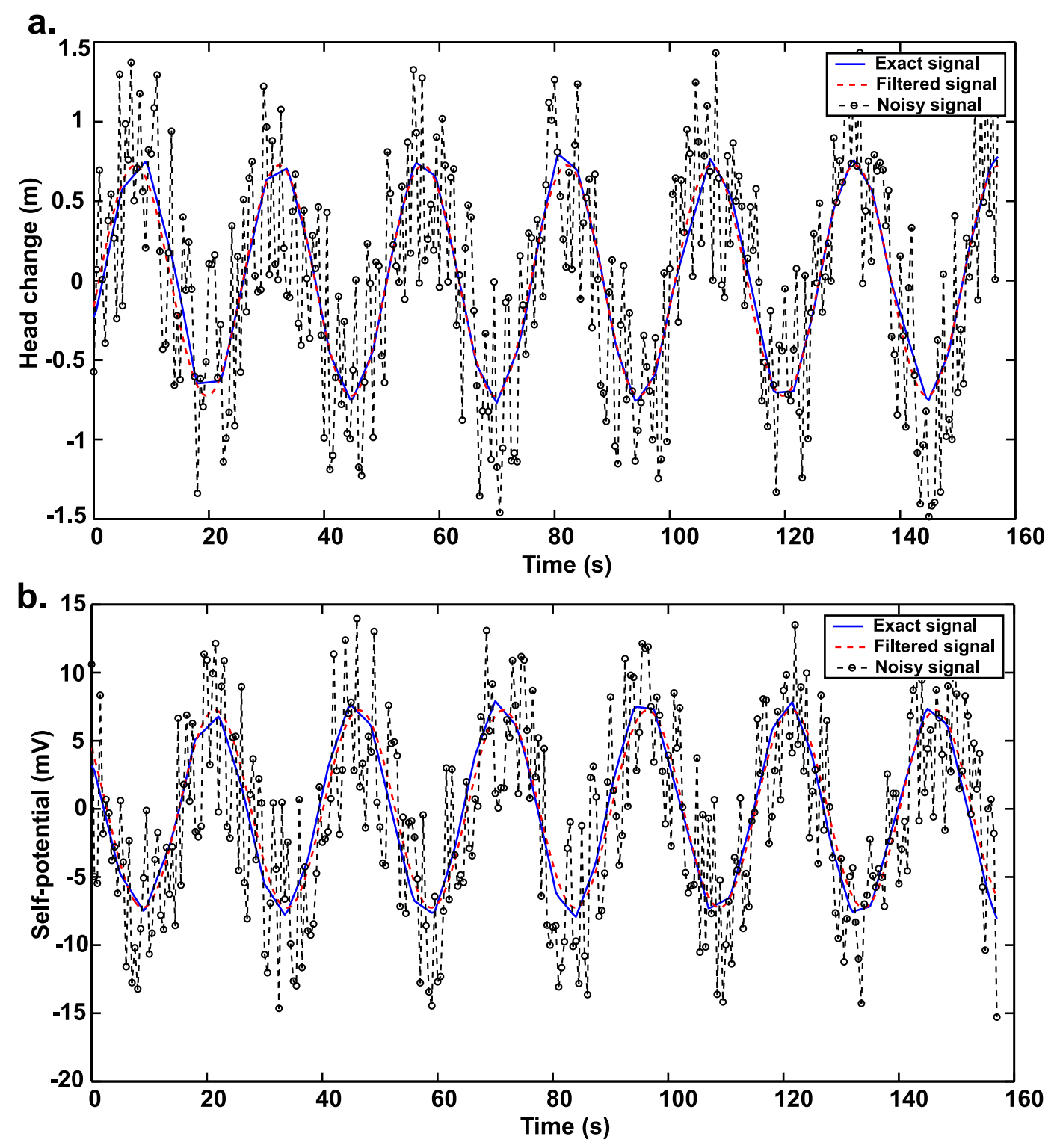

Figure 4. Time variations of the hydraulic head and self-potential response generated with the true parameters. (a) Time variation of hydraulic head. (b) Time variation of self-potential signal. We can see that both signals are harmonic. We added white noise to both signals. Despite the low signal-to-noise ratio (SNR) of true signals, the least squares signal processing technique allows for efficiently filtering the corrupted signal and though recovering the true one.

and

$$
\mathbf{C}=\left(\begin{array}{cc}
\cos \left(\omega t_{1}\right) & \sin \left(\omega t_{1}\right) \\
\cos \left(\omega t_{2}\right) & \sin \left(\omega t_{2}\right) \\
\vdots & \vdots \\
\cos \left(\omega t_{d}\right) & \sin \left(\omega t_{d}\right)
\end{array}\right) .
$$

Finding $\gamma$ is equivalent to solving a least squares problem which solution is given by

$$
\tilde{\gamma}=\left(\mathbf{C}^{\top} \mathbf{C}\right)^{-1} \mathbf{C} \gamma .
$$



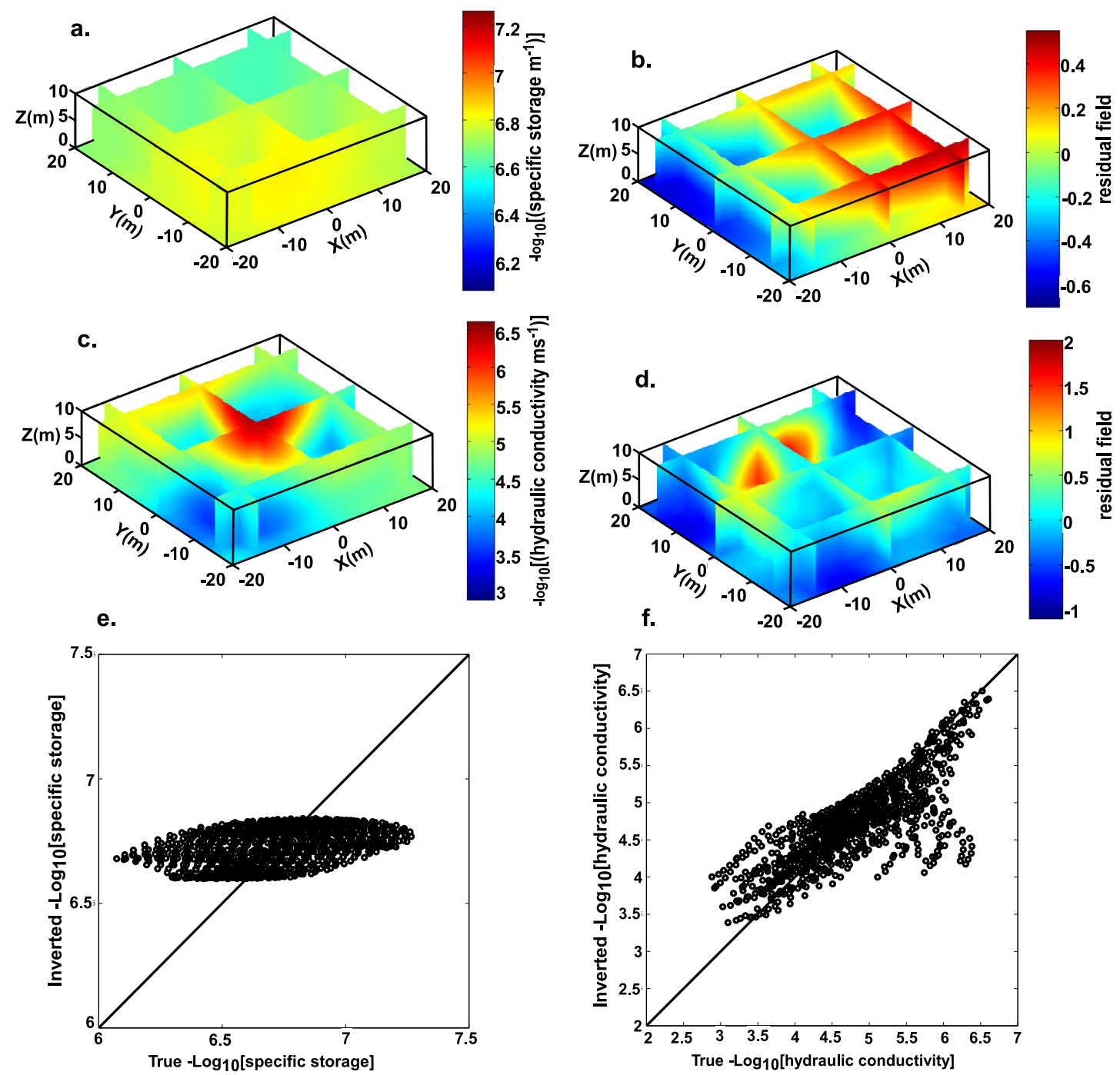

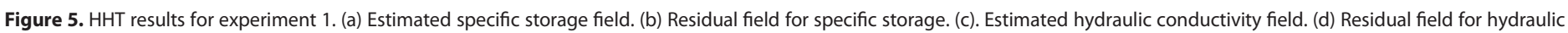
conductivity. (e) Estimated specific storage versus true specific storage. (f) Estimated hydraulic conductivity versus true hydraulic conductivity. 286 hydraulic head measurements were used during the inversion. The estimated fields are globally smooth even though the hydraulic conductivity field is slightly better estimated.

Note that in our case, the error term $e$ is always given by a white noise having zero mean.

Figure 4 shows filtered hydraulic and electric signals recorded while performing harmonic pumping tests. As one can see, the signals contain several cycles but there is no need to use the entirety of the cycles in the inversion process. Nonetheless, enough cycles must be considered to take into account the so-called "memory effect" that may occur in some media. The electrode used to record the self-potential time variation is located at $(0,0$, and $9.6 \mathrm{~m})$ and the hydraulic head was monitored at the location $(0,0$, and $5 \mathrm{~m})$. We notice that despite the fact that the noise amplitude is much higher than the signals amplitudes, we manage to properly recover the true signals and adequately extract the information contained in it.

\subsection{Experiment 1}

In this case study, our goal is to simultaneously reconstruct the fields $S_{s}$ and $K$ while supposing perfect knowledge of the electrical conductivity field of the aquifer. We first perform a harmonic pumping test by using a single port in the central well (see the red dot in the center of Figure 1a). Then, we monitor the head change on all the remaining ports and used these data to simultaneously invert the $S_{s}$ and $K$ as 

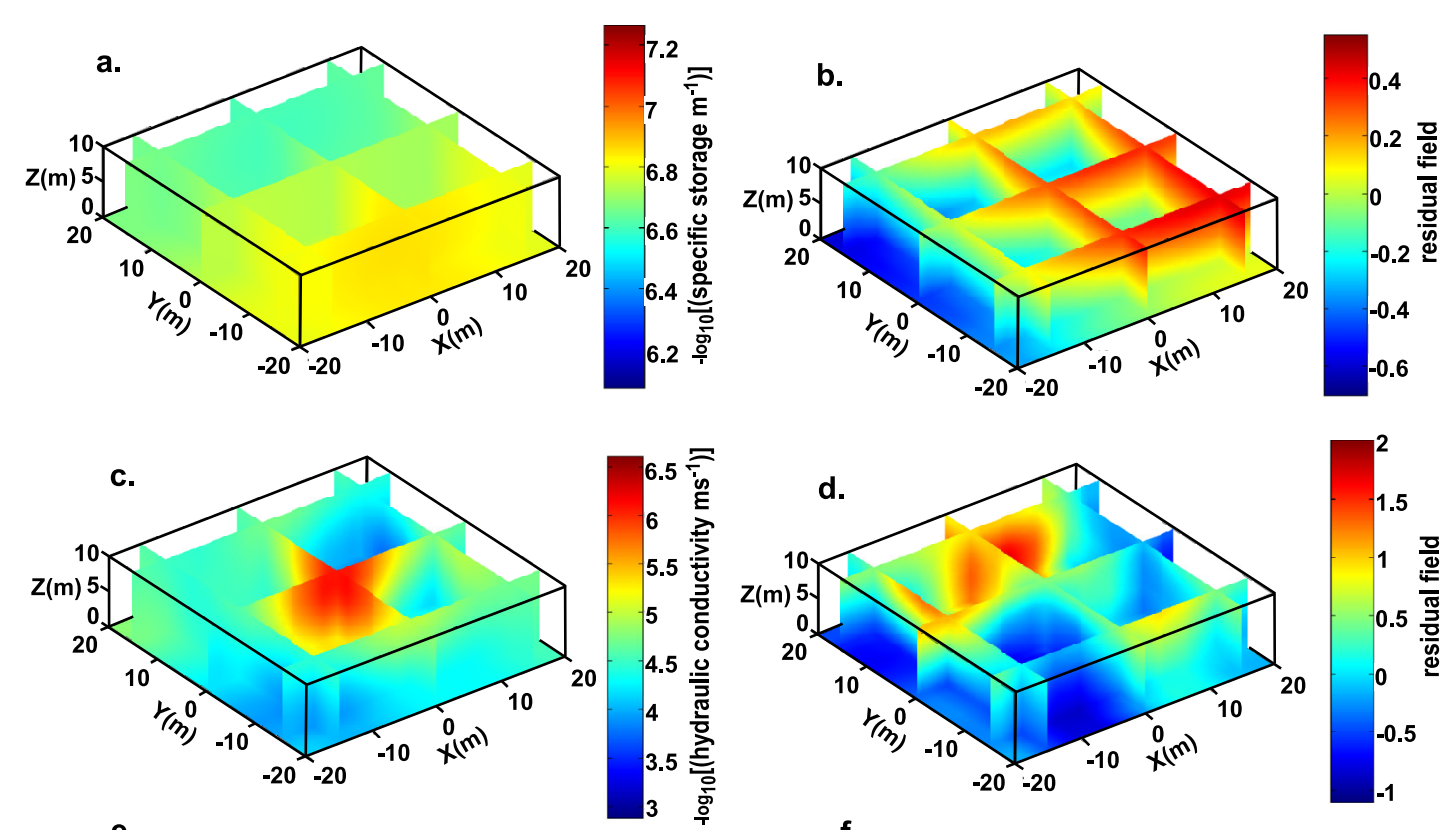

e.

f.
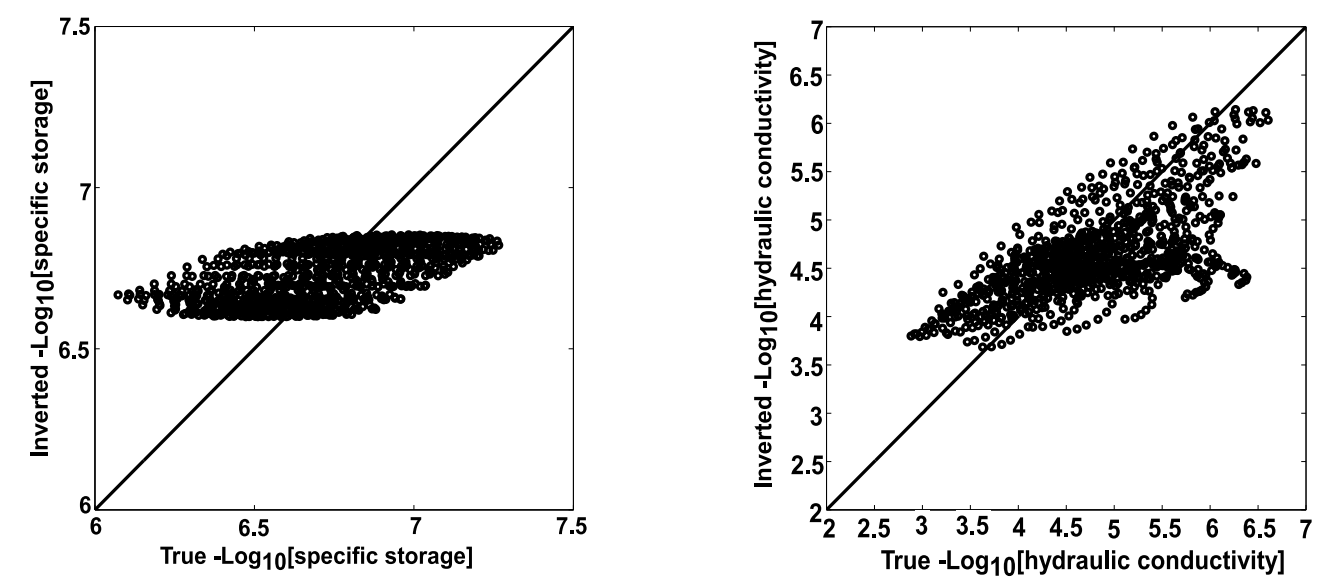

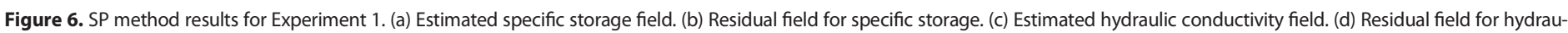

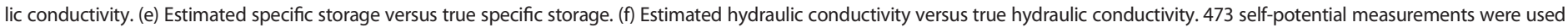
during the inversion. The estimated fields are quite smooth but some heterogeneities are revealed even if their magnitudes are somewhat different from their true magnitudes.

explained below. A total of 286 head measurements are recorded during this HHT survey. Figure 5a shows the estimated $S_{s}$ field. Its resolution is quite low and this field does not reflect any of the main heterogeneities of the true $S_{s}$ field. This observation is confirmed by the $S_{s}$ residual field (Figure $5 \mathrm{~b}$ ) which indeed exhibits a high error rate and the scatterplot of the true $S_{s}$ field versus the estimated $S_{s}$ field which does not follow a linear trend (Figure 5e).

Figure $5 c$ shows that the estimation of the $K$ field is slightly better as the heterogeneity located in central area are well retrieved in the tomogram of the hydraulic conductivity. The $K$ residual field (see Figure $5 \mathrm{~d}$ ) shows a relative decrease in the vicinity of the port used for the stimulation and even in other areas close to the boundary, suggesting that the frequency used for creating the harmonic stimulation manages to reveal some information about the spatial heterogeneities of these areas. Similarly, the hydraulic conductivity scatterplot shows some linear behavior (see Figure $5 f$ ).

We now simulate the recording of the self-potential anomalies generated by using the same harmonic stimulation as before and we simultaneously invert the $S_{s}$ and $K$ fields. The estimated $S_{s}$ field is roughly equivalent (compare Figure $5 \mathrm{a}$ to Figure $6 \mathrm{a}$ and Figure $5 \mathrm{e}$ to Figure $6 \mathrm{e}$ ) to the one estimated from the head data 


\begin{tabular}{|c|c|c|c|c|c|c|}
\hline \multirow[b]{2}{*}{ Study Cases } & & \multicolumn{2}{|c|}{ Mean Squared Error } & \multicolumn{2}{|c|}{$\begin{array}{c}\text { Coefficient of } \\
\text { Determination } R^{2}\end{array}$} & \multirow[b]{2}{*}{ Computational Time } \\
\hline & & $S_{s}$ & $\mathrm{~K}$ & $S_{S}$ & $\mathrm{~K}$ & \\
\hline \multirow[t]{3}{*}{ Experiment 1} & HHT & 0.052 & 0.2442 & 0.1511 & 0.5936 & $1322.5 \mathrm{~s}$ \\
\hline & SP & 0.0444 & 0.3697 & 0.2857 & 0.3848 & $3309.2 \mathrm{~s}$ \\
\hline & Joint & 0.0553 & 0.3567 & 0.1098 & 0.4064 & $3870.3 \mathrm{~s}$ \\
\hline \multirow[t]{3}{*}{ Experiment 2} & HHT & 0.0390 & 0.1795 & 0.3725 & 0.7012 & $9673.5 \mathrm{~s}$ \\
\hline & SP & 0.0673 & 0.1120 & 0.4938 & 0.8136 & $17540 \mathrm{~s}$ \\
\hline & Joint & 0.0232 & 0.0714 & 0.6274 & 0.8811 & $17768 \mathrm{~s}$ \\
\hline Experiment 3 & Joint & 0.0247 & 0.0574 & 0.6027 & 0.9045 & $17943 \mathrm{~s}$ \\
\hline ERT & \multicolumn{3}{|c|}{0.0029 on $\sigma$} & \multicolumn{2}{|c|}{0.9317 on $\sigma$} & $401.4 \mathrm{~s}$ \\
\hline
\end{tabular}

alone. The $K$ field estimated from the self-potential data alone (Figures $6 c$ and $6 d$ ) reveals the central heterogeneity of the $K$ field (like by using the head data alone). The heterogeneities near the boundaries of the domain are slightly less well retrieved than those estimated from the hydraulic head alone. This is confirmed by the mean square errors reported in Table 2.

We now perform the tomography of the hydraulic parameters from the joint inversion of the hydraulic head and the self-potential data. The result of this inversion is shown in Figure 7. Qualitatively, the $S_{s}$ tomogram is similar to those obtained during the previous tests and no obvious improvement is observed by the naked eye. However, the mean square errors and the $R^{2}$ coefficient of determination show that $S_{s}$ is slightly better estimated. The estimated $K$ field successfully shows the central heterogeneities with high resolution and some of the boundary heterogeneities. At the same time, the result of the inversion omits some of the heterogeneities resulting in a tiny increase of the mean square error and $R^{2}$ coefficient.

In this experiment combining the HHT and the SP method slightly improved the $S_{s}$ field resolution and almost did not bring any new information about the $K$ field. At this stage, one can ask a legitimate question: is the SP method indeed useful for estimating the hydraulic parameters and is it worth to be combined with $\mathrm{HHT}$ ?

The answer to this question can be done in two steps. The aforementioned experiment, even if it was reduced to one single stimulation, shows that the SP method gave roughly the same results as the HHT alone. Since an SP array is easy to set up and does not require any expensive drilling, it will be interesting to consider the use of this method in the future. Another part of the answer will be given in the next experiment. How the SP method perform if we use multiple frequencies stimulations?

\subsection{Experiment 2}

In the second experiment, the simultaneous estimation of the hydraulic parameters is done by using five harmonic stimulations whose frequencies are discussed in Figure 1a. We chose low-frequencies stimulations to obtain more information on the heterogeneities at a broader scale [e.g., Cardiff et al., 2013]. We assume that the electrical conductivity field is perfectly known and we start the inversion with homogenous hydraulic parameters corresponding to the geometrical means of the true hydraulic parameters.

First, we invert the hydraulic parameters via HHT by only using the hydraulic heads recorded in a hydraulic tomography fashion, i.e., we perform a harmonic pumping test with a known frequency, we monitor the hydraulic changes in all ports of the aquifer then we switch to another location and we perform a new harmonic pumping test and so on. This is repeated for five distinct ports. Such survey resulted in 1430 hydraulic head measurements. Figures $8 \mathrm{a}, 8 \mathrm{~b}$, and $8 \mathrm{e}$ show results related to the $S_{s}$ obtained from the HHT. We can observe that the main heterogeneities of the $S_{s}$ field are recovered even though the magnitudes of the heterogeneities are not totally recovered. There is a major improvement in the resolution of the $S_{s}$ tomogram compared to the results of Experiment 1. 

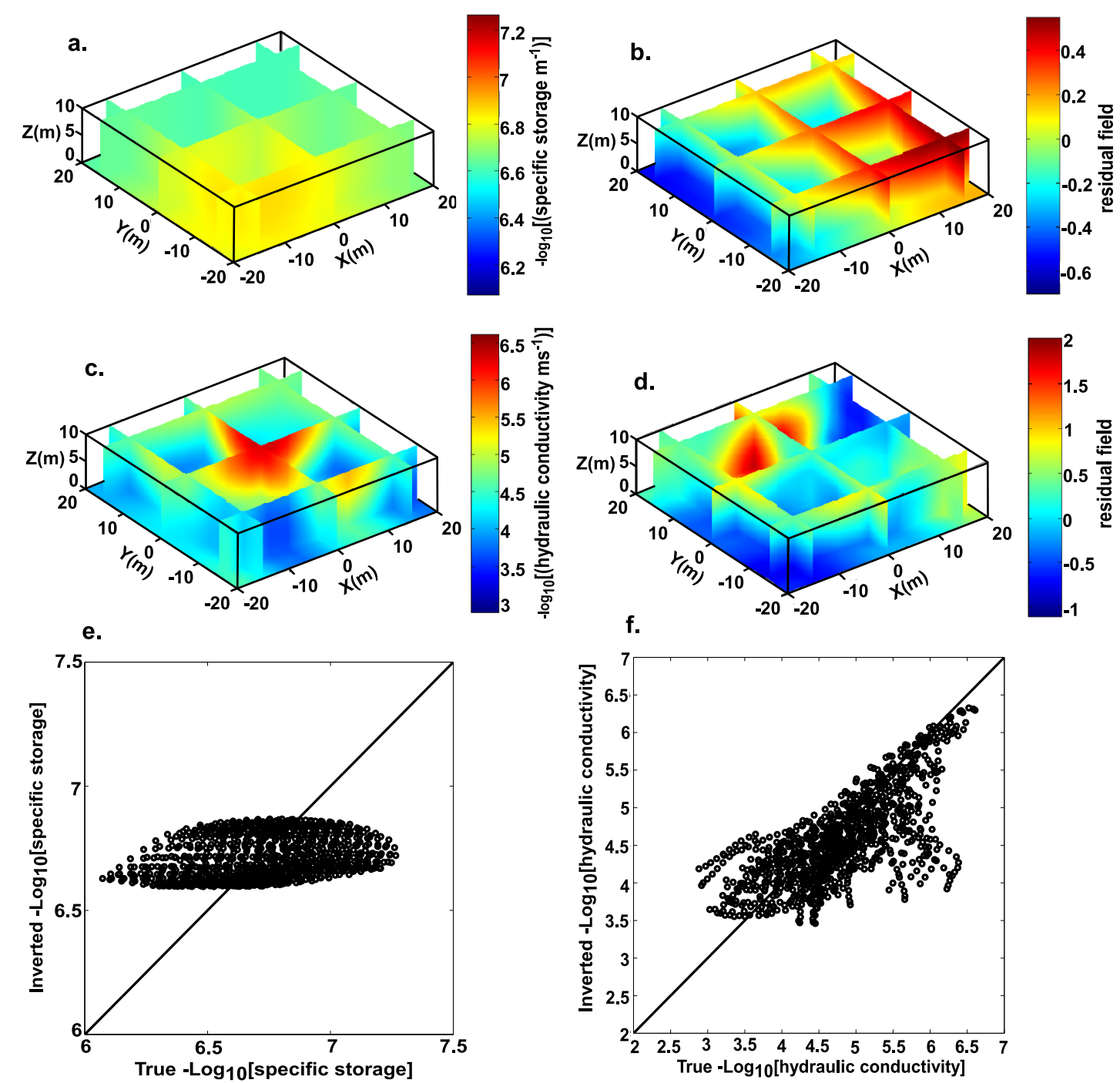

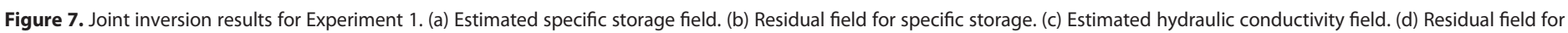
hydraulic conductivity. (e) Estimated specific storage versus true specific storage. (f) Estimated hydraulic conductivity versus true hydraulic conductivity. We notice an improvement in the tomograms especially for the hydraulic conductivity field. Both heterogeneities shapes and their magnitudes have been improved.

The estimation of the $K$ field is shown in Figure 8c. The dominant heterogeneities are captured yet the resolution is still low to reveal the small heterogeneities. Figure 9 shows the results when we only use the SP method to reconstruct the hydraulic parameters. We see that with the SP data, the estimated $K$ field is better than the HHT alone as illustrated by the $K$ residual field (see Figure $9 \mathrm{~d}$ ) and the mean square error ( 0.1795 for HHT versus 0.1120 for SP) and $R^{2}$ ( 0.7012 for HHT versus 0.8136 for SP). The SP method also gave globally better results for the estimation of the $S_{s}$ field (see Figures $9 \mathrm{a}$ and $9 \mathrm{~b}$ ) even if some areas are better recovered by the $\mathrm{HHT}$. There is therefore a complementarity between the $S_{s}$ tomograms estimated using the SP method and HHT. This clearly motivates the need for a joint inversion of the hydraulic head and selfpotential data.

Figure 10 illustrates the results of such joint inversion. Qualitatively, the $S_{s}$ field is well-recovered (Figure $10 a)$ both in terms of the localization of the heterogeneities and their magnitudes. Quantitatively, there is a decrease in the residual field (see Figure 10b) as well as the mean square errors in line with an augmentation of the value of $R^{2}$. Regarding the $K$ field, all its heterogeneities are reconstructed with high resolution (Figure 10c), in line with a significant decrease of the mean square error and accompanied by 

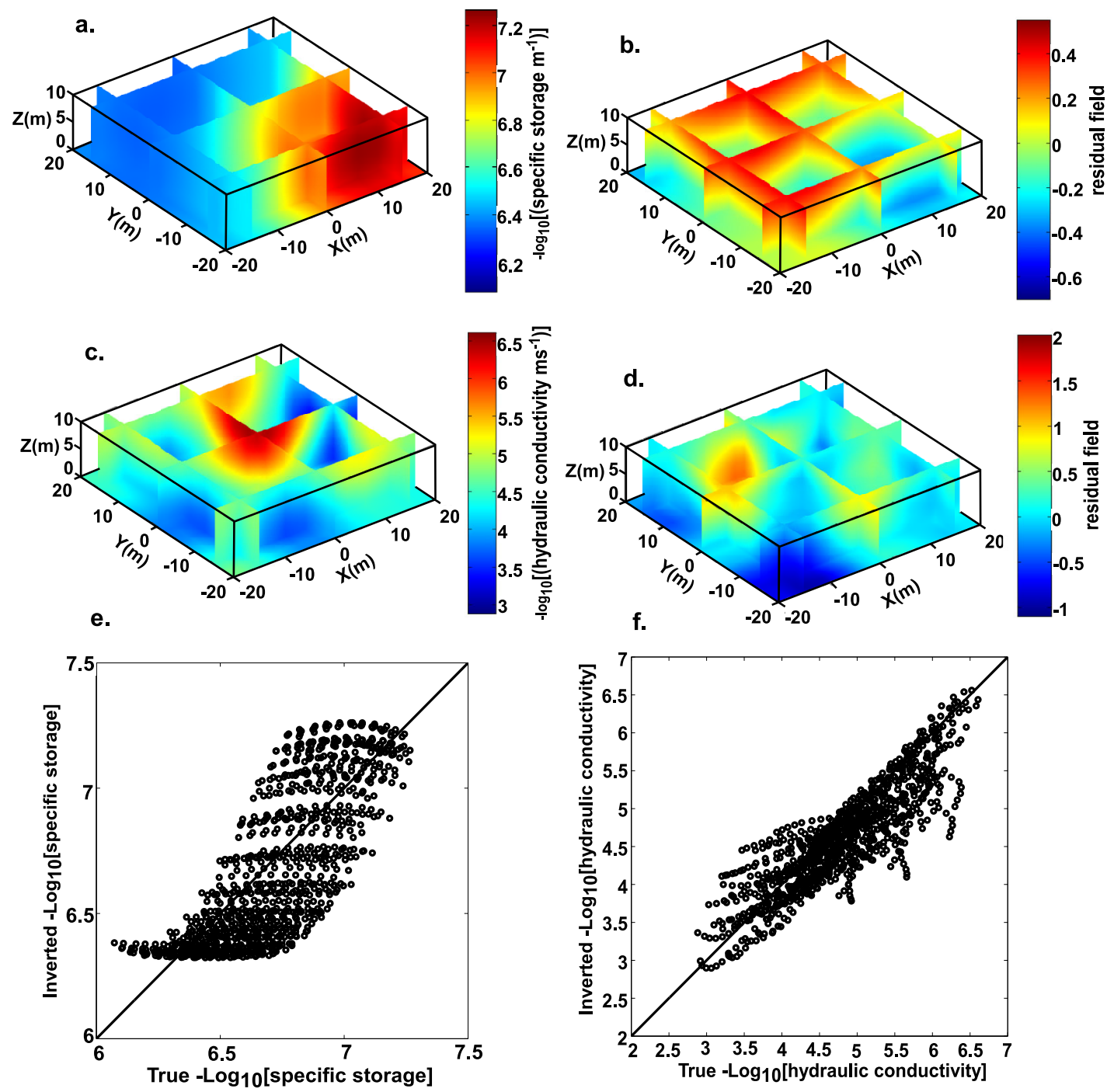

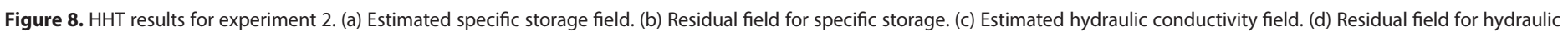
conductivity. (e) Estimated specific storage versus true specific storage. (f) Estimated hydraulic conductivity versus true hydraulic conductivity. Five multifrequency harmonic pumping tests are performed (see Figure 1a) and 1430 hydraulic head measurements are collected and used during the inversion. There is significant improvement compared to the results HHT in Experiment 1. The major heterogeneities are identified and the residual field shows a global decrease of the estimation errors.

a good increase of the $R^{2}$ coefficient. This point is indeed confirmed by the low generalized values of the $K$ residual field (Figure 10d). The plots of the true hydraulic parameters fields versus the estimated hydraulic parameter fields show an improvement of the reconstruction of the hydraulic parameters spatial distributions (Figures 10e and 10f). A conclusion that can be drawn from this experiment is that multifrequency HHT is indeed an efficient tool for imaging the spatial hydraulic parameters distribution. Since the self-potential signals are directly related to the flow, they provide additional information on those distributions. Therefore, a good strategy is to entirely utilize the complementarity of information provided by both methods, by combining them to better characterize the distribution of the hydraulic parameters.

\subsection{Experiment 3}

The previous experiment showed that significant improvement in the tomography of the hydraulic parameters can be obtained by combining HHT and SP. That said, the SP method is sensitive to the knowledge of 

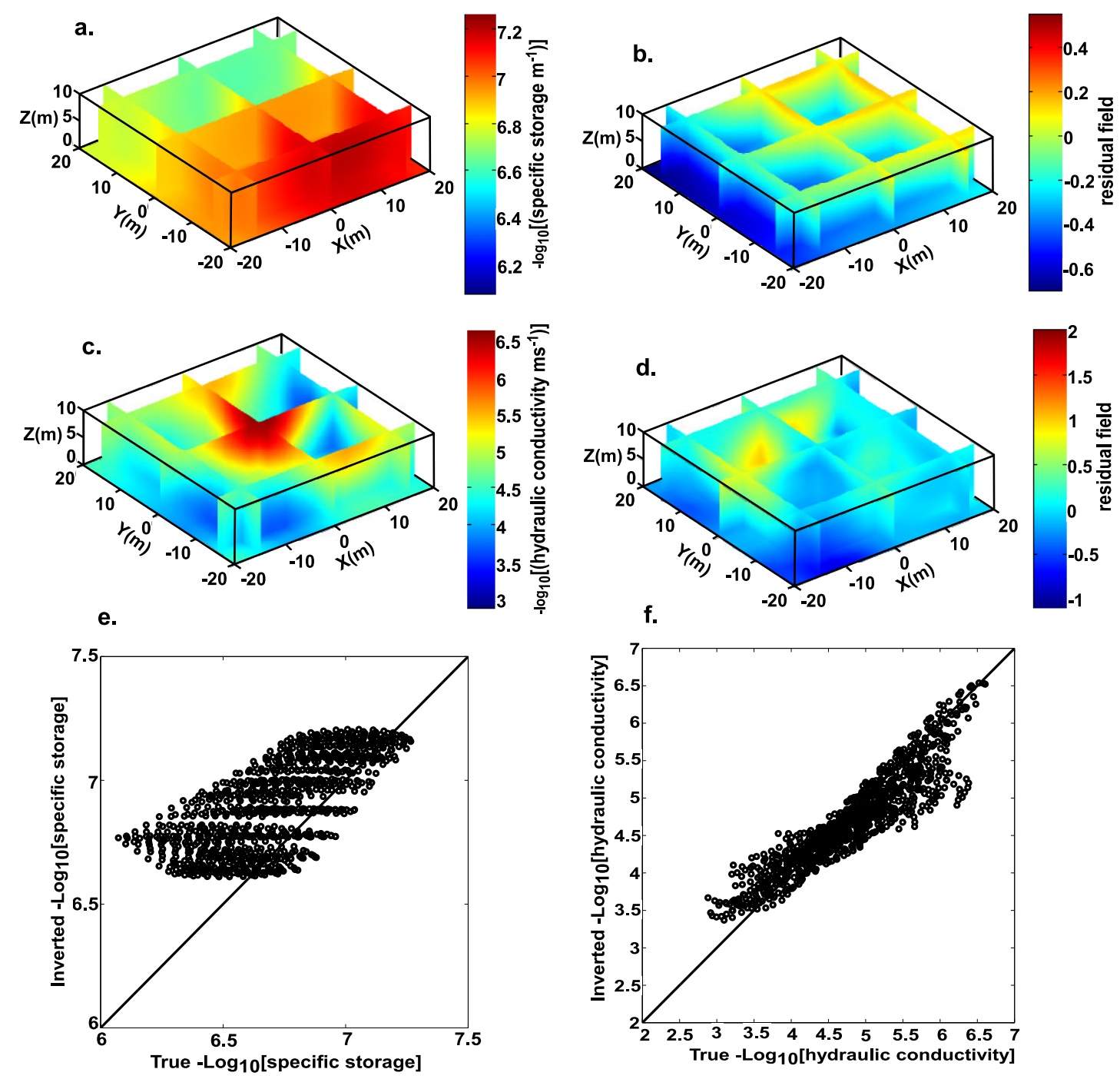

Figure 9. SP method results for Experiment 2. (a) Estimated specific storage field. (b) Residual field for specific storage. (c) Estimated hydraulic conductivity field. (d) Residual field for hydraulic conductivity. (e) Estimated specific storage versus true specific storage. (f) Estimated hydraulic conductivity versus true hydraulic conductivity. A total of 2365 self-potential measurements were recorded during this SP survey. The specific storage tomogram shows an important improvement as illustrated by the specific storage residual field. The hydraulic conductivity tomogram is approximately similar to the one obtained with HHT and reflects the major spatial heterogeneities of the hydraulic conductivity field.

the electrical conductivity field (see discussion in Soueid Ahmed et al. [2014]). However, when working in real field applications, we do not know the heterogeneities of the electrical conductivity field. In practice, we need to accomplish an ERT to estimate those heterogeneities. Therefore, we decide to simulate a resistivity survey to capture, with a certain degree of precision, the conductivity distribution.

Implementing an ERT is numerically similar to implementing a steady state hydraulic tomography. Indeed, the electrical potential equation is given by

$$
\nabla \cdot(\sigma \nabla V)=l,
$$

where $\sigma$ is the electrical conductivity $\left(\mathrm{S} \mathrm{m}^{-1}\right), V$ is the electrical potential field (in $\mathrm{V}$ ), and $I$ is the injected current $(A)$. Both problem shares the same partial differential equation.

We used the same 30 electrodes network used for the SP method (see Figure 1b) and the electrical potential measurements were collected using a dipole-dipole configuration. Five current injection of -1 and $1 \mathrm{~mA}$ were made, resulting in 205 measurements. The measurements were then introduced as data 

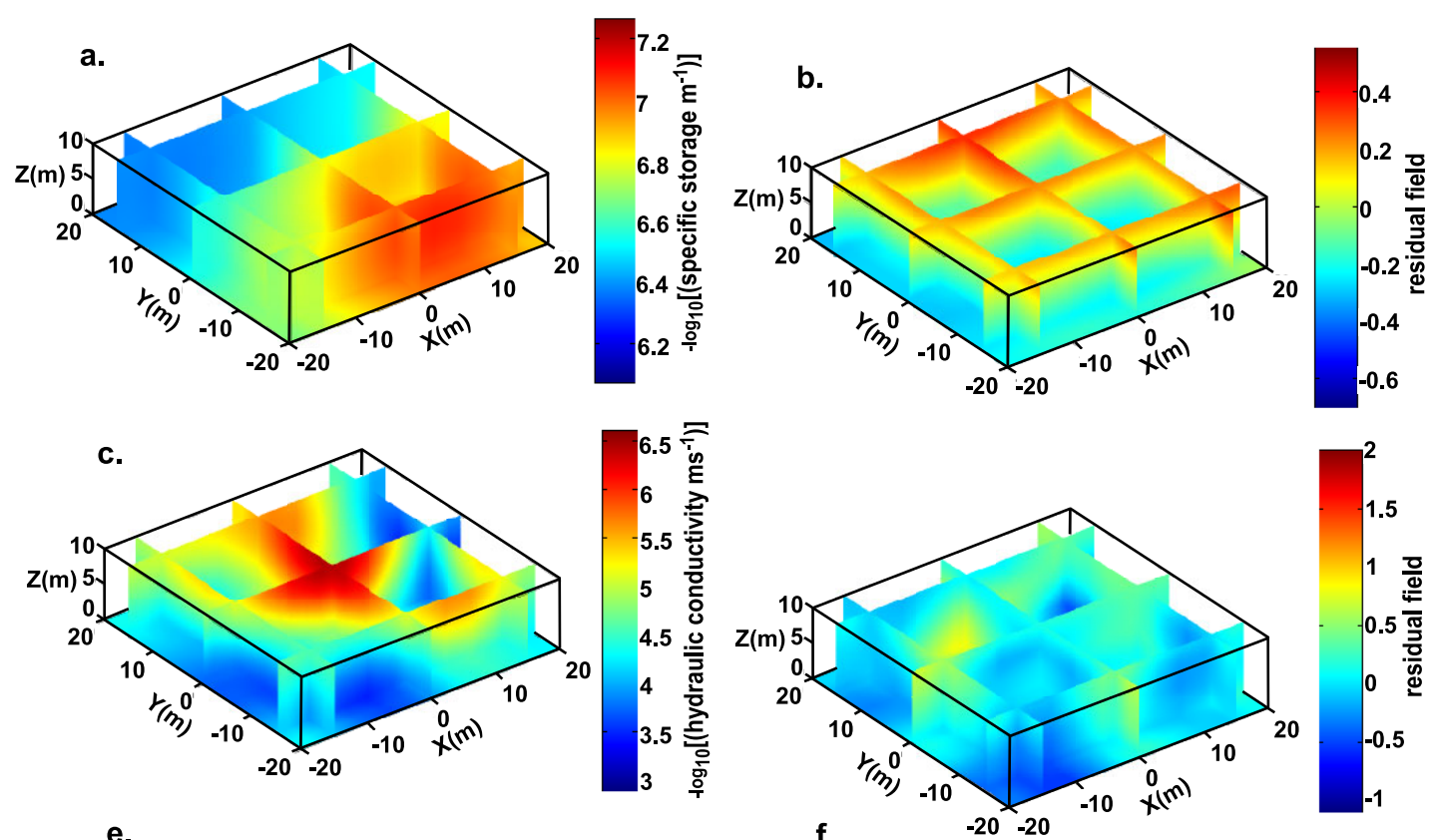

e.

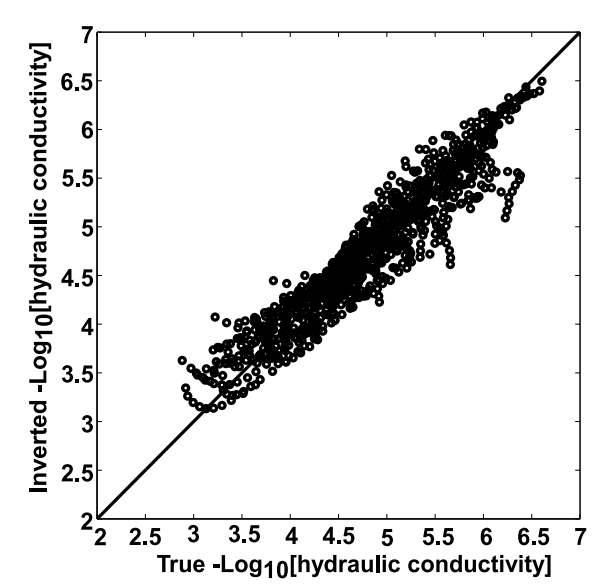

Figure 10. Joint inversion results for Experiment 2. (a) Estimated specific storage field. (b) Residual field for specific storage. (c) Estimated hydraulic conductivity field. (d) Residual field for hydraulic conductivity. (e) Estimated specific storage versus true specific storage. (f) Estimated hydraulic conductivity versus true hydraulic conductivity. We can observe that both

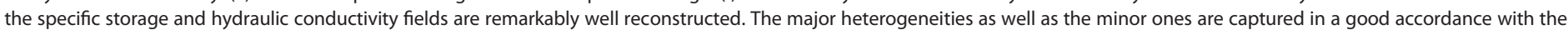
range of magnitudes. Additionally, the uncertainties in the estimates are very low.

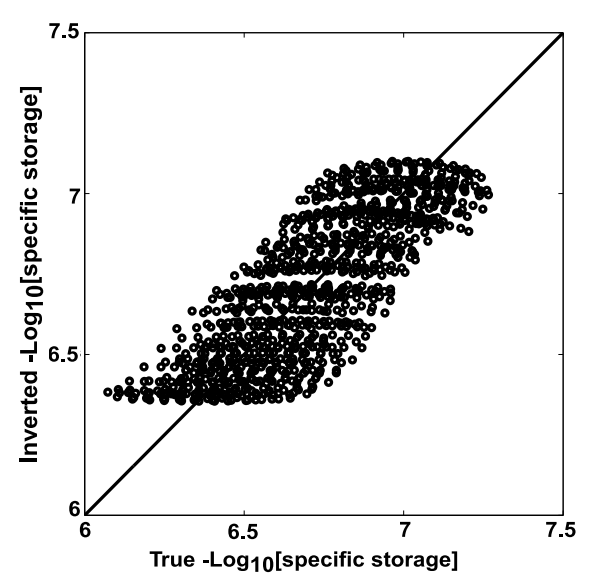



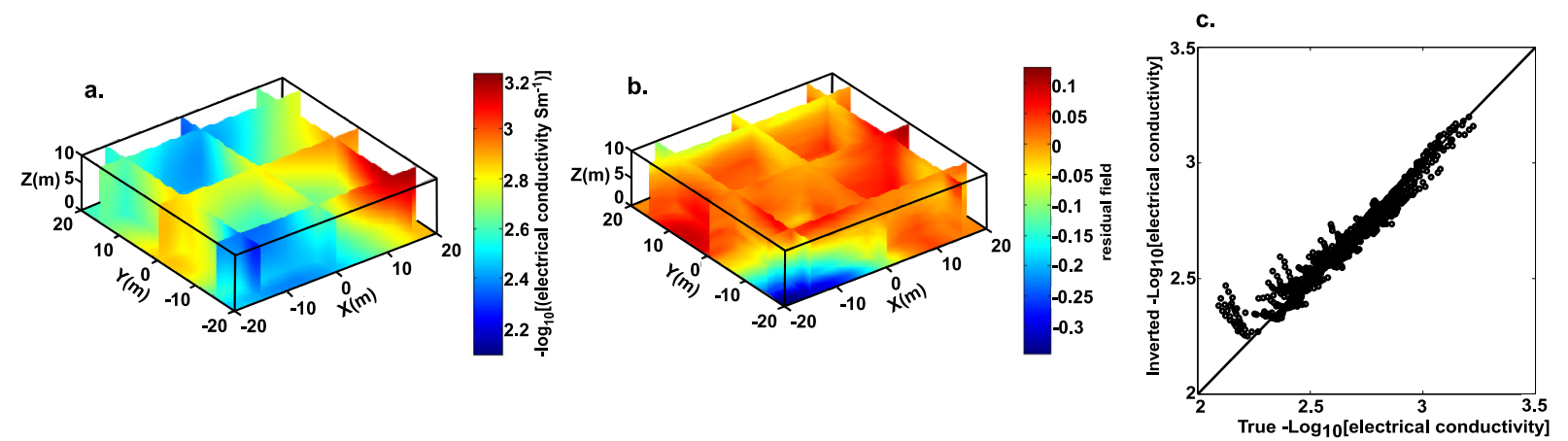

Figure 11. Electrical resistivity tomography results. (a) Estimated electrical conductivity field. (b) Residual field for electrical conductivity. (c) Estimated electrical conductivity versus true electrical conductivity. We performed five injection tests resulting in 205 electrical potential measurements which are be used for estimating the electrical conductivity field. We can notice that the reconstruction has high resolution and the residual field show very low uncertainties.
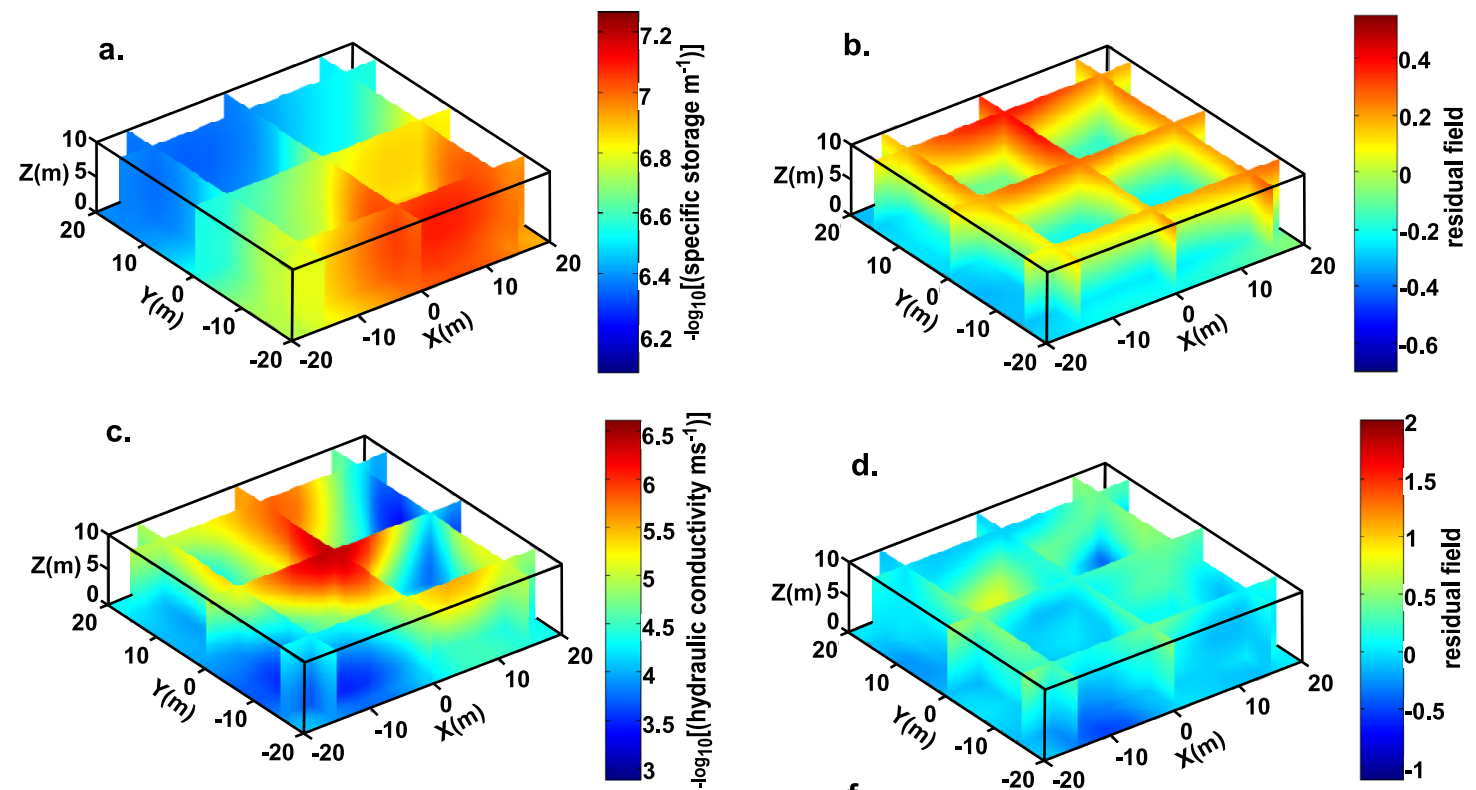

e.
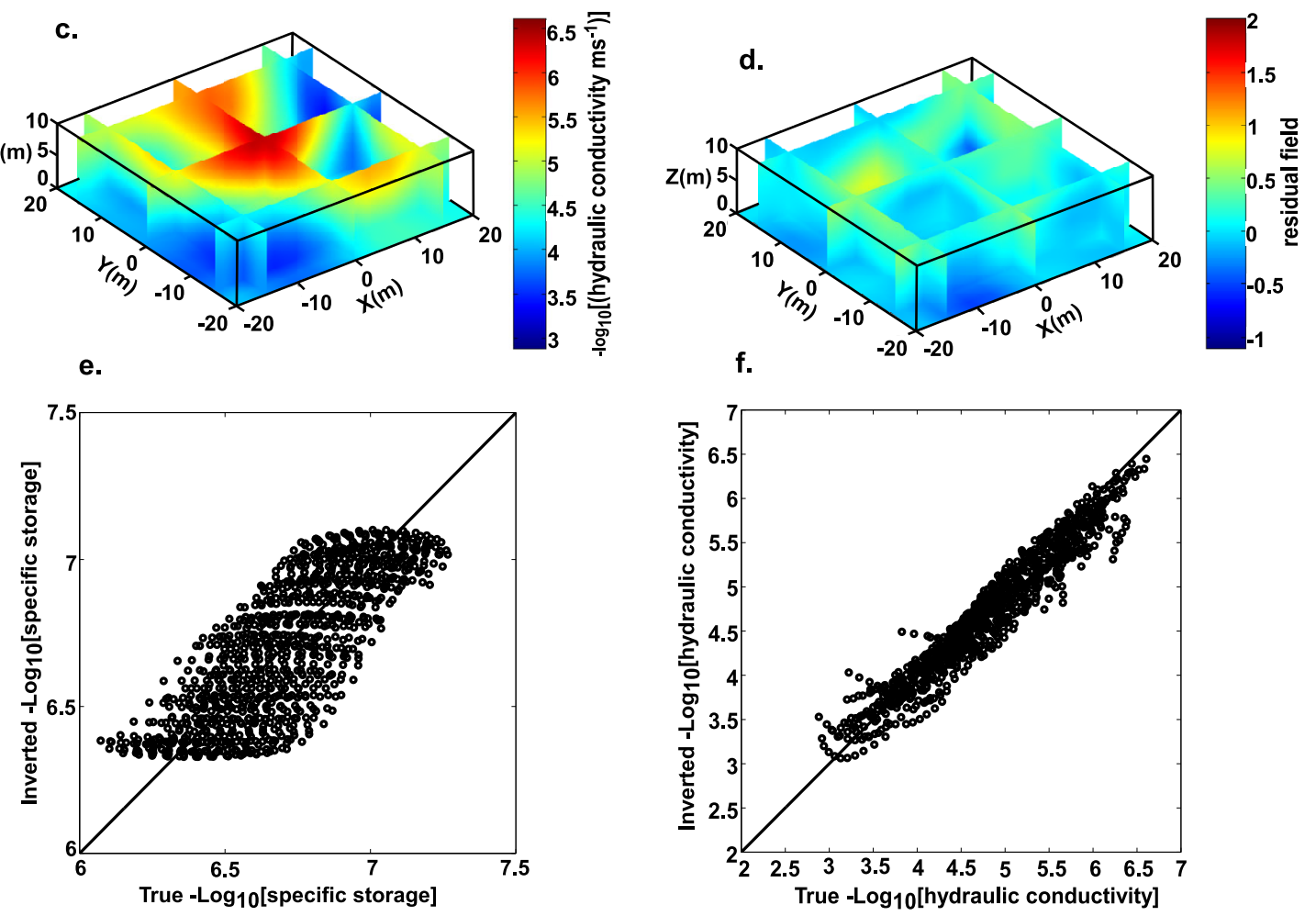

Figure 12. Joint inversion results for Experiment 3. (a) Estimated specific storage field. (b) Residual field for specific storage. (c) Estimated hydraulic conductivity field. (d) Residual field for hydraulic conductivity. (e) Estimated specific storage versus true specific storage. (f) Estimated hydraulic conductivity versus true hydraulic conductivity. These results were obtained under conditions which are exactly similar to those under which Experiment 2 was performed. We can see that we obtained the same results as those obtained in Experiment 2 . This proves that the efficiency of our approach is not weakened by the low uncertainties in the electrical conductivity field that can be caused by the ERT. 


\section{QAGU Water Resources Research}
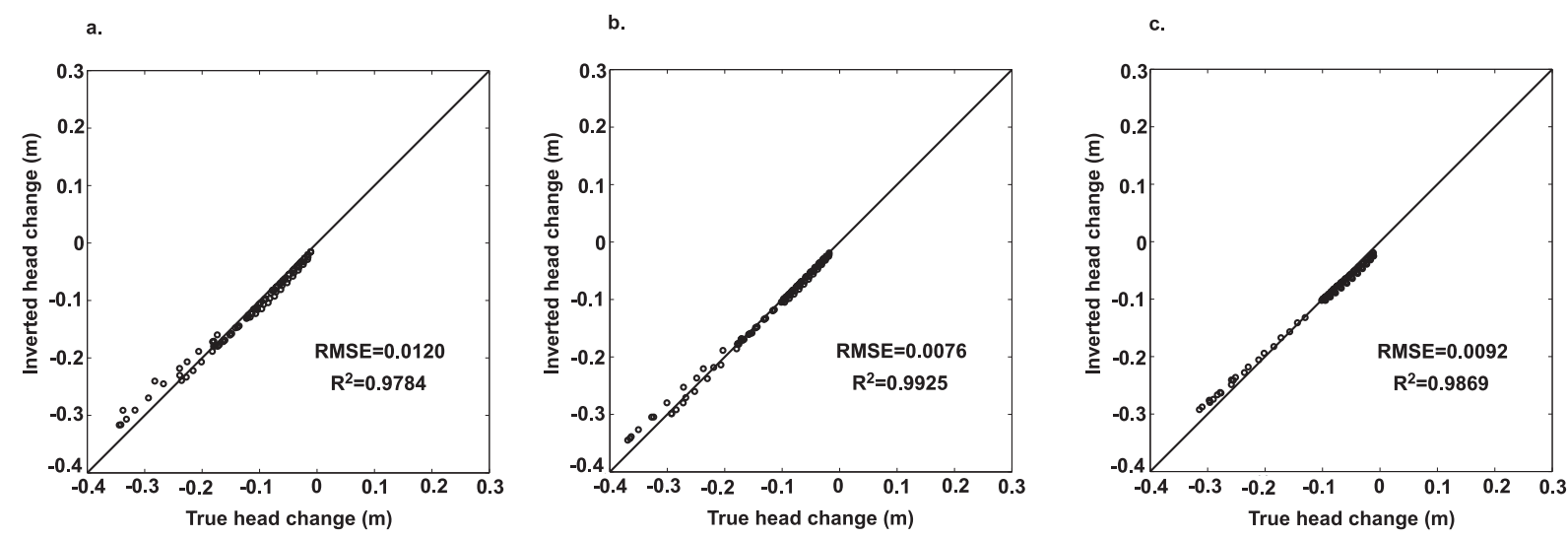

Figure 13. Cross-validation results. (a) PZ1 pumping test results. (b) PZ2 pumping test results. (c) PZ3 pumping test results. Harmonic pumping tests are performed in a well and the head changes are recorded on the other wells. We used the Root Mean Squared Error (RMSE) as well as the coefficient of determination $R^{2}$ to assess the performances of our inversion results. Both techniques show that the measurements are very well reconstructed.

ground surface in recovering the hydraulic conductivity and specific storage fields. In addition, to better assess the efficiency of our estimated models, we perform a sequence of three independent pumping tests that are not used in the calibration effort but only for validation. The results of such cross validation are shown in Figure 13. We can see that the computed hydraulic head data and the true ones have a perfect match.

\section{Conclusion}

We assessed the efficiency of a robust hydrogeophysical approach to perform the tomography of the hydraulic conductivity using piezometric heads and self-potential data. Numerical simulations of harmonic pumping tests show the two advantages in using sinusoidal signal for the hydraulic stimuli: (1) the response can be efficiently extracted from the ambient sources of noise and (2) employing harmonic stimulations with multiple frequencies allows for a progressive and full exploration of the medium heterogeneities. We also used self-potential data as an additional source of information. Indeed, the flow of the groundwater motion generates an electrical potential known as the streaming potential. The resulting electrical signature can be recorded at the ground surface to study the groundwater flow as well as gathering relevant information about the subsurface hydraulic parameters. We combined the HHT and the SP method for the large-scale inversion of the saturated specific storage and hydraulic conductivity of a heterogeneous unconfined aquifer using a hydroelectric model based on the coupling of the Richards equation and the Poisson equation for the hydraulic and electrical problems, respectively. The dimensionality reduction used in our analysis enabled us to reach drastic computational benefits, making our approach very tractable for real-world applications.

Our numerical experiments revealed that even with a stimulation using one single frequency, the SP method was capable of capturing some of the major heterogeneities of the field. That said, it did not bring in this case an important improvement in the inversion results, compared to the HHT alone.

Although, our work was limited to synthetic data, we applied our methodology under conditions which are similar to those that can be encountered in real field conditions. Future works should include: (i) Working on real-field data or using fully controlled laboratory sandbox experiments. (ii) Modeling of the nonlinearity phenomena is observed in streaming potential signals because of hysteresis of the hydraulic conductivity and capillary pressure in the capillary fringe. (iii) Using recently developed stochastic large scale inversion techniques. (iv) Studying of the impact of varying frequencies of stimulations on the reconstruction of the local heterogeneities. We implemented a large scale ERT survey to estimate the electrical conductivity field. We showed that our approach provided inversion results that are as accurate for the joint inversion of selfpotential data as those obtained when assuming perfect knowledge of the electrical conductivity field. This result comforted us in the high potentiality and promising aspect of our approach when moving forward to real field applications. 


\section{Acknowledgments}

We thank LABEX OSUG@2020 for funding the project HYDROGEO "Couplage géophysique et hydrogéologique pour caractériser les écoulements hydriques dans les vallées alpines." We thank the Associate Editor as well as three anonymous reviewers for their insightful and constructive reviews. The numerical data used in this manuscript are uploaded as Supporting Information data sets.

\section{References}

Ahmad, M. U. (1969), A laboratory study of streaming potentials, Geophys. Prospect., 12(1), 49-64.

Ahn, S., and R. N. Horne (2010), Estimating permeability distributions from pressure pulse testing, in Proceedings of the SPE Annual Technical Conference and Exhibition, Florence, Italy, p. 16, Soc. of Pet. Eng., Richardson, Tex., doi:10.2118/134391-MS.

Alkafeef, S., R. J. Gochin, and A. L. Smith (2001), The effect of double layer overlap on measured streaming currents for toluene flowing through sandstone flowing through sandstone cores, Colloids Surf. A, 195, 77-80.

Bakhos, T., M. Cardiff, W. Barrash, and P. K. Kitanidis (2014), Data processing for harmonic pumping tests, J. Hydrol., 511, 310-319, doi: 10.1016/j.jhydrol.2014.01.007.

Berg, S. J., and W. A. Illman (2011), Three-dimensional transient hydraulic tomography in a highly heterogeneous glaciofluvial aquiferaquitard system, Water Resour. Res., 47, W10507, doi:10.1029/2011WR010616.

Binley, A., S. S. Hubbard, J. A. Huisman, A. Revil, D. A. Robinson, K. Singha, and L. D. Slater (2015), The emergence of hydrogeophysics for improved understanding of subsurface processes over multiple scales, Water Resour. Res., 51, 3837-3866, doi:10.1002/ 2015 WR017016.

Cardiff, M., and W. Barrash (2011), 3-D transient hydraulic tomography in unconfined aquifers with fast drainage response, Water Resour. Res., 47, W12518, doi:10.1029/2010WR010367.

Cardiff, M., W. Barrash, and P. K. Kitanidis (2012), A field proof-of-concept of aquifer imaging using 3-D transient hydraulic tomography with modular, temporarily-emplaced equipment, Water Resour. Res., 48, W05531, doi:10.1029/2011WR011704.

Cardiff, M., T. Bakhos, P. K. Kitanidis, and W. Barrash (2013), Aquifer heterogeneity characterization with harmonic pumping: Sensitivity analysis and imaging potential, Water Resour. Res., 49, 5395-5410, doi:10.1002/wrcr.20356.

Chapman, D. L. (1913), A contribution to the theory of electrocapillarity, Philos. Mag., 25, 475-481, doi:10.1080/14786440408634187.

Chen, J., S. S. Hubbard, and Y. Rubin (2001), Estimating the hydraulic conductivity at the South Oyster Site from geophysical tomographic data using Bayesian techniques based on the normal linear regression model, Water Resour. Res., 37(6), 1603-1613, doi:10.1029/ 2000WR900392.

Chidichimo, F., M. De Biase, E. Rizzo, S. Masi, and S. Straface (2015), Hydrodynamic parameters estimation from self-potential data in a controlled full scale site, J. Hydrol., 522, 572-581, doi:10.1016/j.jhydrol.2015.01.022.

Cirpka, O. A., and P. K. Kitanidis (2000), Sensitivity of temporal moments calculated by the adjoint-state method and joint inversing of head and tracer data, Adv. Water Resour., 24(1), 89-103.

Davis, J. A., R. O. James, and J. Leckie (1978), Surface ionization and complexation at the oxide/water interface, J. Colloid Interface Sci., 63, 480-499, doi:10.1016/0021-9797(78)90217-5

Deutsch, C., and A. Journel (1992), GSLIB: Geostatistical Software Library and User's Guide, Oxford Univ. Press, N. Y.

Domenico, P. A., and M. D. Mifflin (1965), Water from low-permeability sediments and land subsidence, Water Resour. Res., 1(4), 563-576, doi:10.1029/WR001i004p00563.

Fienen, M. N., T. Clemo, and P. K. Kitanidis (2008), An interactive Bayesian geostatistical inverse protocol for hydraulic tomography, Water Resour. Res., 44, W00B01, doi:10.1029/2007WR006730.

Fokker, P. A., E. S. Borello, C. Serazio, and F. Verga (2012), Estimating reservoir heterogeneities from pulse testing, J. Pet. Sci. Eng., 86, 15-26, doi:10.1016/j.petrol.2012.03.017.

Fokker, P. A., J. Renner, and F. Verga (2013), Numerical modeling of periodic pumping tests in wells penetrating a heterogeneous aquifer, Am. J. Environ. Sci., 9, 1-13, doi:10.3844/ajessp.2013.1.13.

$\mathrm{Fu}$, J., and J. Gomez-Hernandez (2009), Uncertainty assessment and data worth in groundwater flow and mass transport modeling using a blocking Markov chain Monte Carlo method, J. Hydrol., 364, 328-341, doi:10.1016/j.jhydrol.2008.11.014.

Halko, N., P. G. Martinsson, and J. A. Tropp (2011), Finding structure with randomness: Probabilistic algorithms for constructing approximate matrix decompositions, SIAM Rev., 53(2), 217-288, doi:10.1137/090771806.

Hirsch, A. I., A. M. Michalak, L. M. Bruhwiler, W. Peters, E. J. Dlugokencky, and P. P. Tans (2006), Inverse modeling estimates of the global nitrous oxide surface flux from 1998-2001, Global Biogeochem. Cycles, 20, GB1008, doi:10.1029/2004GB002443.

Hollaender, F., P. Hammond, and A. C. Gringarten, (2002), Harmonic testing for continuous well and reservoir monitoring, in SPE Annual Technical Conference and Exhibition, Soc. of Pet. Eng., San Antonio, Tex., doi:10.2118/77692-MS.

Huang, S.-Y., J.-C. Wen, T.-C. J. Yeh, W. Lu, H.-L. Juan, C.-M. Tseng, J.-H. Lee, and K.-C. Chang (2011), Robustness of joint interpretation of sequential pumping tests: Numerical and field experiments, Water Resour. Res., 47, W10530, doi:10.1029/2011WR010698.

Illman, W. A., X. Liu, S. Takeuchi, T.-C. J. Yeh, K. Ando, and H. Saegusa (2009), Hydraulic tomography in fractured granite: Mizunami Underground Research site, Japan, Water Resour. Res., 45, W01406, doi:10.1029/2007WR006715.

Illman, W. A., J. Zhu, A. J. Craig, and D. Yin (2010), Comparison of aquifer characterization approaches through steady state groundwater model validation: A controlled laboratory sandbox study, Water Resour. Res., 46, W04502, doi:10.1029/2009WR007745.

Jardani, A., A. Revil, and J. P. Dupont (2006), Self-potential tomography applied to the determination of cavities, Geophys. Res. Lett., 33, L13401, doi:10.1029/2006GL026028.

Jardani, A., A. Revil, A. Bolève, A. Crespy, J. P. Dupont, W. Barrash, and B. Malama (2007), Tomography of the Darcy velocity from selfpotential measurements, Geophys. Res. Lett., 34, L24403, doi:10.1029/2007GL031907.

Jardani, A., A. Revil, W. Barrash, A. Crespy, E. Rizzo, S. Straface, M. Cardiff, B. Malama, C. Miller, and T. Johnson (2009), Reconstruction of the water table from self-potential data: A Bayesian approach, Ground Water, 47(2), 213-227, doi:10.1111/j.17456584.2008.00513.x.

Jardani, A., A. Revil, and J. P. Dupont (2013), Stochastic joint inversion of hydrogeophysical data for salt tracer test monitoring and hydraulic conductivity imaging, Adv. Water Resour., 52, 62-77, doi:10.1016/j.advwatres.2012.08.005.

Kitanidis, P. K. (1995), Quasi-linear geostatistical theory for inversing, Water Resour. Res., 31(10), 2411-2419.

Kitanidis, P. K. (1996), On the geostatistical approach to the inverse problem, Adv. Water Resour., 19(6), 333-342.

Kitanidis, P. K., and J. Lee (2014), Principal component geostatistical approach for large-dimensional inverse problems, Water Resour. Res., 50, 5428-5443, doi:10.1002/2014WR015483.

Kuo, C. H. (1972), Determination of reservoir properties from sinusoidal and multirate flow tests in one or more wells, SPE J., 12, 499-507, doi:10.2118/3632-PA.

Lee, J., and P. K. Kitanidis (2014), Large-scale hydraulic tomography and joint inversion of head and tracer data using the Principal Component Geostatistical Approach (PCGA), Water Resour. Res., 50, 5410-5427, doi:10.1002/2014WR015483.

Li, W., W. Nowak, and O. A. Cirpka (2005), Geostatistical inverse modeling of transient pumping tests using temporal moments of drawdown, Water Resour. Res., 41, W08403, doi:10.1029/2004WR003874. 
Liu, S., T.-C. J. Yeh, and R. Gardiner (2002), Effectiveness of hydraulic tomography: Sandbox experiments, Water Resour. Res., 38(4), 1034, doi:10.1029/2001WR000338.

Liu, X., W. A. Illman, A. J. Craig, J. Zhu, and T.-C. J. Yeh (2007), Laboratory sandbox validation of transient hydraulic tomography, Water Resour. Res., 43, W05404, doi:10.1029/2006WR005144.

Maineult, A., E. Strobach, and J. Renner (2008), Self-potential signals induced by periodic pumping tests, J. Geophys. Res., 113, B01203, doi: 10.1029/2007JB005193.

Malama, B., A. Revil, and K. L. Kulhman (2009a), A semi-analytical solution for transient streaming potentials associated with confined aquifer pumping tests, Geophys. J. Int., 176, 1007-1016, doi:10.1111/j.1365-246X.2008.04014.x.

Malama, B., K. L. Kuhlman, and A. Revil (2009b), Theory of transient streaming potentials associated with axial-symmetric flow in unconfined aquifers, Geophys. J. Int., 179, 990-1003, doi:10.1111/j.1365-246X.2009.04336.x.

Mao, D., T.-C. J. Yeh, L. Wan, J.-C. Wen, W. Lu, C.-H. Lee, and K.-C. Hsu (2013), Joint interpretation of sequential pumping tests in unconfined aquifers, Water Resour. Res., 49, 1782-1796, doi:10.1002/wrcr.20129.

Michalak, A. M., and P. K. Kitanidis (2004), Estimation of historical ground water contaminant distribution using the adjoint state method applied to geostatistical inverse modeling, Water Resour. Res., 40, W08302, doi:10.1029/2004WR003214.

Michalak, A. M., L. Bruhwiler, and P. P. Tans (2004), A geostatistical approach to surface flux estimation of atmospheric trace gases, J. Geophys. Res., 109, D14109, doi:10.1029/2003JD004422.

Ozaki, Y, Mikada, H., Goto, T., and Takekawa, J. (2014), Self-potential inversion for the estimation of permeability structure, J. Environ. Eng. Geophys., 19(3), 193-199, doi:10.3997/2352-8265.20140134.

Pollock, D., and O. A. Cirpka (2010), Fully coupled hydrogeophysical inversion of synthetic salt tracer experiments, Water Resour. Res., 46, W07501, doi:10.1029/2009WR008575.

Rabinovich, A., W. Barrash, M. Cardiff, D. L. Hochstetler, T. Bakhos, G. Dagan, and P. K. Kitanidis (2015), Frequency dependent hydraulic properties estimated from harmonic pumping tests in an unconfined aquifer, J. Hydrology, 531, 2-16, doi:10.1016/ j.jhydrol.2015.08.021.

Rasmussen, T. C., K. G. Haborak, and M. H. Young (2003), Estimating aquifer hydraulic properties using sinusoidal pumping at the Savannah River Site, South Carolina, USA, Hydrogeol. J., 11, 466-482, doi:10.1007/s10040-003-0255-7.

Revil, A., and A. Jardani (2013), The Self-Potential Method, Theory and Applications in Environmental Geosciences, Cambridge Univ. Press, Cambridge, U. K.

Revil, A., and H. Mahardika (2013), Coupled hydromechanical and electromagnetic disturbances in unsaturated clayey materials, Water Resour. Res., 49, 744-766, doi:10.1002/wrcr.20092.

Revil, A., H. Schwaeger, L. M. Cathles III, and P. D. Manhardt (1999), Streaming potential in porous media: 2. Theory and application to geothermal systems, J. Geophys. Res., 104(B9), 20,033-20,048, doi:10.1029/1999JB900090.

Revil, A., V. Naudet, J. Nouzaret, and M. Pessel (2003), Principles of electrography applied to self-potential electrokinetic sources and hydrogeological applications, Water Resour. Res., 39(5), 1114, doi:10.1029/2001WR000916.

Revil, A., C. Gevaudan, N. Lu, and A. Maineult (2008), Hysteresis of the self-potential response associated with harmonic pumping tests, Geophys. Res. Lett., 35, L16402, doi:10.1029/2008GL035025.

Revil, A., M. Karaoulis, T. Johnson, and A. Kemna (2012), Review: Some low-frequency electrical methods for subsurface characterization and monitoring in hydrogeology, Hydrogeol. J., 20(4), 617-658, doi:10.1007/s10040-011-0819-x.

Richards, L. A. (1931), Capillary conduction of liquids through porous media, Physics, 1, 318-333.

Rizzo, E., B. Suski, A. Revil, S. Straface, and S. Troisi (2004), Self-potential signals associated with pumping tests experiments, J. Geophys. Res., 109, B10203, doi:10.1029/2004JB003049.

Schwanghart, W. (2008), Variogram.m, MathWorks, Natick, Mass. [Available at http://www.mathworks.com/matlabcentral/fileexchange/ 20355-experimental-semi-variogram.]

Semenov, A. S. (1980), Elektrorazvedka Metodom Estestvennogo Elektricheskogo Polia, 2nd ed., 445 pp., Nedra, Leningrad, Russia.

Sill, W. R. (1983), Self-potential modeling from primary flows, Geophysics, 48, 76-86, doi:10.1190/1.1441409.

Sneed, M. (2001), Hydraulic and mechanical properties affecting ground-water flow and aquifer system compaction, San Joaquin Valley, California, U.S. Geol. Surv. Open File Rep., 01-35, 26 pp.

Soueid Ahmed, A., A. Jardani, A. Revil, and J. P. Dupont (2014), Hydraulic conductivity field characterization from the joint inversion of hydraulic heads and self-potential data, Water Resour. Res., 50, 3502-3522, doi:10.1002/2013WR014645.

Soueid Ahmed, A., A. Jardani, A. Revil, and J. P. Dupont (2015), HT2DINV: A 2D forward and inverse code for steady-state and transient hydraulic tomography problems, Comput. Geosci., 85, 36-44, doi:10.1016/j.cageo.2013.05.008.

Soueid Ahmed, A., A. Jardani, A. Revil, and J. P. Dupont (2016), Specific storage and hydraulic conductivity tomography through the joint inversion of hydraulic heads and self-potential data, Adv. Water Resour., 89, 80-90, doi:10.1016/j.advwatres.2016.01.006.

Straface, S., T.-C. J. Yeh, J. Zhu, S. Troisi, and C. H. Lee (2007), Sequential aquifer tests at a well field, Montalto Uffugo Scalo, Italy, Water Resour. Res., 43, W07432, doi:10.1029/2006WR005287.

Sun, R., T.-C. J. Yeh, D. Mao, M. Jin, W. Lu, and Y. Hao (2013), A temporal sampling strategy for hydraulic tomography analysis, Water Resour. Res., 49, 3881-3896, doi:10.1002/wrcr.20337.

Suski, B., A. Revil, K. Titov, P. Konosavsky, C. Dagès, M. Voltz, and O. Huttel (2006), Monitoring of an infiltration experiment using the selfpotential method, Water Resour. Res., 42, W08418, doi:10.1029/2005WR004840.

Tikhonov, A. N., and V. I. Arsenin (1977), Solutions of III-Posed Problems, V.H. Winston \& Sons, Washington, D. C.

Titov, K., A. Revil, P. Konasovsky, S. Straface, and S. Troisi (2005), Numerical modeling of self-potential signals associated with a pumping test experiment, Geophys. J. Int., 162, 641-650, doi:10.1111/j.1365-246X.2005.02676.x.

Toll, N. J., and T. C. Rasmussen (2007), Removal of barometric pressure effects and earth tides from observed water levels, Ground Water, 45, 101-105, doi:10.1111/j.1745-6584.2006.00254.x.

van Genuchten, M. T. (1980), A closed-form equation for predicting the hydraulic conductivity of unsaturated soils, Soil Sci. Soc. Am. J., 44, 892-898.

Vinogradov, J., and M. D. Jackson (2011), Multiphase streaming potential in sandstones saturated with gas/brine and oil/brine during drainage and imbibition, Geophys. Res. Lett., 38, L01301, doi:10.1029/2010GL045726.

Vogel, C. R. (2002), Computational Methods for Inverse Problems, vol. 23, Soc. of Ind. and Appl. Math., Philadelphia, Pa.

Yeh, T. C. J., and S. Liu (2000), Hydraulic tomography: Development of a new aquifer test method, Water Resour. Res., 36(8), 2095-2105, doi: $10.1029 / 2000$ WR900114.

Yeh, T. C. J., and J. Zhu (2007), Hydraulic/partitioning tracer tomography for characterization of dense nonaqueous phase liquid source zones, Water Resour. Res., 43, W06435, doi:10.1029/2006WR004877. 
Yeh, T.-C. J., M. Jin, and S. Hanna (1996), An iterative stochastic inverse method: Conditional effective transmissivity and hydraulic head fields, Water Resour Res., 32(1), 85-92, doi:10.1029/95WR02869.

Yeh, T.-C. J., J. Xiang, R. M. Suribhatla, K.-C. Hsu, C.-H. Lee, and J. C. Wen (2009), River stage tomography: A new approach for characterizing groundwater basins, Water Resour. Res., 45, W05409, doi:10.1029/2008WR007233.

Zhao, Z., W. A. Illman, T. C. J. Yeh, S. J. Berg, and D. Mao (2015), Validation of hydraulic tomography in an unconfined aquifer: A controlled sandbox study, Water Resour. Res., 51, 4137-4155, doi:10.1002/2015WR016910.

Zhu, J., and T. C. J. Yeh (2005), Characterization of aquifer heterogeneity using transient hydraulic tomography, Water Resour. Res., 41 , W07028, doi:10.1029/2004WR003790. 